\title{
Modelling the impact of climate change risk on supply chain performance
}

\begin{abstract}
Climate change is among the top global risks due to its growing adverse impact on businesses. However, few empirical studies address this imminent risk from a supply chain perspective. Due to a lack of established approaches for capturing complex interaction between climate change risk and supply chain performance, a three-phase mixed methodology approach was attempted. A cognitive map first captured the inter-relationships based on a mental model established by a group of experts. Later, a survey gathered from industry practitioners assessing causal relationships identified key climate change factors and most influenced supply chain performance dimensions. Finally, a system dynamics model supported by multiple case scenarios assessed the implications of climate change on supply chain performance. The results indicated a significant reduction in the availability of natural resources/raw material and capacity, leading to increase in stock-outs, inventory costs and bottlenecks disrupting procurement, manufacturing and logistics functions. Supply chain performance captured through efficiency and effectiveness shows a negative trend with increasing climate change consequences. The systems approach followed in this paper contributes by providing a quantitative model for assessing the impact of climate change risk on supply chain performance.
\end{abstract}

Keywords: Supply chain performance, Climate change, Performance measurement, Climate risk, Uncertainty, Systems theory

\section{Introduction}

Climate change is an inevitable risk faced by today's supply chains. Climate change and supply chains are found to mutually influence each other through natural disasters and greenhouse gas (GHG) emissions, respectively (Ghadge et al., 2020). Recent literature on supply chain management attempts to capture the impact of SC operations on climate change (e.g., Sousa Jabbour et al., 2018; Dahlmann and Roehrich, 2019). However, climate change also affects SC operations in multiple ways. Various industries such as agriculture, forestry and mining are exposed to the direct and indirect impact of climate change (Sussman and Freed, 2008; 
Gasbarro et al., 2017). Overconsumption of these natural resources has led to the escalation of climate change. This exogenous risk can significantly impact organisation's operational and financial performance (Agrawala et al., 2011; Bergmann et al., 2016; Lim-Camacho et al., 2017). Existing climate models indicate that climate change and its cascading effects will continue to impact global supply chains in the future (OECD, 2015, Andreoni and Miola, 2014; Li et al., 2019). Thus, organisations should work together to develop climate resilient Supply Chain (SC) networks. To build such capability within SCs, comprehensive understanding of mutually-influencing relationship and their impact is essential.

Climate change impacts various entities and functional levels in supply chains, and their ripple effect leads to risk propagation along the entire SC network (Ghadge et al., 2020). However, investigation of the implications of climate change from SC perspective is limited and in its early stages (Fleming et al., 2014; Alves et al., 2017; Lim-Camacho et al., 2017). Despite few conceptual or theoretical developments, there is an evident lack of empirical/analytical studies attempting to capture the holistic interaction between climaterelated risks and SC operations (Ghadge et al., 2020). In general, studies attempting to quantify the impact of climate change are inadequate due to the high inherent uncertainty of the topic, lack of suitable data, and complexity in modelling an uncertain problem (Andreoni and Miola, 2014; Melkonyan et al., 2017).

The motivation behind this study is the lack of holistic analytical modelling approaches to develop climate change scenarios at the SC level, earlier identified by Ghadge et al. (2020). According to Alves et al. (2017), controlling and monitoring climate contingencies at the SC level should be permanent and systematic. This requires developing a thorough understanding of the direct and immediate impact of climate change as well as long-term, cascading effects resulting from the climate variability. Analysing these changes on SC performance indicators is a good starting point to measure and assess these direct and cascading effects. Thus, this study aims to quantify the impact of climate change risk on SC performance. In order to achieve this aim, the study models the aggregated impact of this risk on identified SC performance metrics as well as overall SC efficiency and effectiveness.

Due to a lack of established approaches for capturing complex interaction between climate change risk and supply chain performance, a three-phase mixed methodology approach was attempted. First, cognitive mapping was used to provide a graphical representation of expert(s) mental model concerning the relations between climate change and business 
operations. Consequently, a survey was developed to gather information about the most influencing variables interfacing between climate change and SC operations from an industry practitioners' perspective. The prominent relations identified from the above methods were modelled and simulated using System Dynamics (SD) approach. Multiple case scenarios with different risk exposure levels were assessed to gain insights into the behaviour of supply chains under different climate change scenarios.

The paper contributes to climate change risk research within the SC context in two ways. First, the proposed cognitive map captures the complex interaction between two domains from the climate change perspective. Past studies have looked at this from the SC perspective. Secondly, to the best of authors' knowledge this is the first comprehensive study attempting to quantify the aggregated impact of climate change risk on overall SC performance, efficiency and effectiveness.

The rest of the paper is presented as provided. Section 2 provides critical literature associated with the impact of climate change on business operations and supply chain performance measurement. The mixed-methodology approach is presented in section 3 . Section 4 explains the three phases of the study, from holistic cognitive mapping to the specified quantitative analysis. Section 5 summarises the results and findings of the developed SD model. Finally, discussion, theoretical implications and future research directions are presented.

\section{Literature review}

\subsection{Impact of climate change on business operations}

Climate-related risks are increasingly threatening the sustainability and competitiveness of organisations and their wider networks (Fleming et al., 2014; Bergmann et al., 2016; Gasbarro et al., 2017). It is well known that climate change leads to rising temperatures, changes in seasons, sea-level rise, unusual weather events and natural disasters. These events may directly or indirectly affect multiple entities within SC networks such as physical infrastructure and assets (e.g., factory, warehouse, energy infrastructure, transportation network), natural resources (e.g., land, water and energy resources, crops, livestock) and workforce (OECD, 2015). To comprehend all possible impact of climate change on business operations, an extensive review of literature was conducted. Table 1 captures a wide range of adverse effects 
of climate change on the performance and competitiveness of organizations. Captured implications from multiple sources (cited in Table 1) range from decreased availability and quality of resources, decreased labour productivity, decline in revenue and profit, increased effort and costs due to new regulations, increased insurance costs and changes in energy demand for cooling and heating. Undoubtedly, climate change risk is of growing interest to business/SC researchers as well as practitioners due to the increased frequency, severity and duration of extreme weather events (e.g., heatwaves, floods, storms, and droughts) (OECD, 2015; Bergmann et al., 2016; Ghadge et al., 2020). Extreme events driven by climate change are found to damage facilities, physical assets, transportation and energy infrastructure and communication systems as evidenced from the literature (Table 1).

There have been few developments on building conceptual or theoretical underpinning. Bergmann et al. (2016) employ comparative analysis to investigate the impact of five types of extreme weather events (heatwave, cold wave, heavy precipitation, storm and drought) on the financial performance of organisations based on natural resource dependence theory. Following contingency theory, Alves et al. (2017) list four contingencies arising from climate change that affect supply chains as: resource scarcity and difficulty of access to raw materials, technological advances, new regulations, and extra costs. Ghadge et al. (2020) emphasise the importance of risk management to cope with climate change following systems theory to propose a conceptual framework for managing climate change risks in supply chains.

Despite these sporadic conceptual or theoretical developments on climate change in SC context, there is an evident lack of empirical/analytical studies that reveal the holistic interaction between climate-related risks and SC performance. Notably, there is an apparent need to quantify various impacts of climate change on different stages of SCs and provide a clear picture of this uncertain and multi-faceted interaction.

\subsection{Supply chain performance measurement}

Performance measurement is the process of developing a set of performance metrics and collecting, analysing, reporting and reviewing performance data to quantify the effectiveness and efficiency of organisations' processes (Bititci, 2015; Bourne et al., 2018). Effectiveness indicates the level to which the customer's requirements are met; whereas efficiency refers to how economically the resources are deployed to fulfil customer orders (Neely et al., 1995). Performance measurement helps to ascertain that an organisation effectively reveals whether processes are under control and whether improvements are required (Akyuz and Erkan, 2010). 
Er-Kara, M., Ghadge, A. \& Bititci, US, (2020), "Modelling the impact of climate change risk on supply chain performance”, International journal of Production Research, Accepted.

Table 1. Challenges faced by businesses due to broad climate change issues

\begin{tabular}{|c|c|c|}
\hline $\begin{array}{l}\text { Challenges faced by businesses due to } \\
\text { broad climate change issues }\end{array}$ & Description of issues & References \\
\hline $\begin{array}{l}\text { Supply problems of raw material } \\
\text { resources } \\
\text { - Extinction or scarcity of some } \\
\text { resources } \\
\text { - Difficulty to access to raw materials } \\
\text { - Decreases in the quality and quantity } \\
\text { of raw materials } \\
\text { - Higher raw material and commodity } \\
\text { prices } \\
\text { - Crop diseases, pests, animal } \\
\text { infections }\end{array}$ & $\begin{array}{l}\text { - Scarcity of agricultural products due to difficulty to grow crops under } \\
\text { changing weather conditions or infectious plant diseases and pests } \\
\text { - Decreased quality of agricultural and forestry raw materials due to diseases or } \\
\text { extreme weather events such as flood } \\
\text { - Water scarcity, lower crop yields and decreased livestock production due to } \\
\text { meteorological, hydrological and agricultural droughts } \\
\text { - Deforestation due to global warming } \\
\text { - Land use changes }\end{array}$ & $\begin{array}{l}\text { Sussman and Freed, 2008; } \\
\text { Thorpe and Fennell, } \\
\text { 2012; Alves et al., } 2017\end{array}$ \\
\hline $\begin{array}{l}\text { Changes in customer behaviour and } \\
\text { demand }\end{array}$ & $\begin{array}{l}\text { - Demand volatility (e.g., increase in demand of some products and services } \\
\text { such as beverages, air conditioners, renewable energy, tourism; decrease in } \\
\text { demand of electricity, residential heating, etc.) } \\
\text { - Changes in market (e.g., increase in demand of environmentally-friendly } \\
\text { products due to environmental awareness) }\end{array}$ & $\begin{array}{l}\text { Agrawala et al., 2011; } \\
\text { Keleş et al., } 2018\end{array}$ \\
\hline Relocation of production & - The necessity to relocate facilities to resilient geographical regions & Andreoni and Miola, 2014 \\
\hline $\begin{array}{l}\text { Changes in the efficiency and } \\
\text { effectiveness of processes }\end{array}$ & $\begin{array}{l}\text { - Increased temperatures may affect the performance of processes and quality } \\
\text { of outcomes }\end{array}$ & Sussman and Freed, 2008 \\
\hline
\end{tabular}


Er-Kara, M., Ghadge, A. \& Bititci, US, (2020), "Modelling the impact of climate change risk on supply chain performance", International journal of Production Research, Accepted.

Changes in product quality

\begin{tabular}{l} 
Decrease in labour performance \\
\hline Damage or destruction of facilities, \\
infrastructure and physical assets
\end{tabular}
infrastructure and physical assets
- Decreased product quality resulting from low quality raw materials affected by climate change (e.g., decrease in coffee quality due to low-quality beans resulting from changing seasons)

- The effects of climate related events (e.g., heat stress) on the productivity of the workforce especially in farming and construction industries

- Damage to facilities, transportation infrastructure, energy networks and communication systems resulting from extreme weather events such as floods, storm, etc.

- Damage to transportation infrastructure and problems in delivery of products and services

\section{Transportation problems}

- Disruption of transportation infrastructure because of climate changerelated disasters

- Delays in delivery of products due to bad weather conditions or weather extremes

\section{Destruction of markets}

- Human migration due to climate change

- Loss of customer base as a result of climate change-related disasters

Extra costs

- Higher prices due to scarcity of resources

- Costs to control growing crop diseases and pests

- Regulation taxes, tariffs and levy rates

- Increased costs due to environmental regulations (e.g., cost of low-carbon technologies)

- Increased energy usage and/or costs
Sussman and Freed, 2008; OECD, 2015

Crawford and Seidel, 2013

Kreie, 2013

Agrawala et al., 2011

Sussman and Freed, 2008;

OECD, 2015

Thorpe and Fennell, 2012;

Agrawala et al., 2011;

Fleming et al., 2014;

Sussman and Freed, 2008;

Alves et al., 2017 
Er-Kara, M., Ghadge, A. \& Bititci, US, (2020), "Modelling the impact of climate change risk on supply chain performance", International journal of Production Research, Accepted.

- Higher insurance and maintenance costs

- Cost of development and adoption of new technologies and innovative solutions (refrigerated transportation and storage systems, climate resilient buildings, temperature regulation technologies in plants, floating agriculture, laser land levelling in agriculture, integration of real time monitoring of weather data $\&$ early warning systems for extreme events, etc.)

Climate related mortality and morbidity

- High temperatures may cause health problems and death of employee and IPCC, 2014; OECD, 2015 customers

- Exposure to extreme heat and cold may decrease the performance of employee

- Spread of infectious diseases

Decreased financial performance

- Decrease in profits and income due to increased commodity prices and Crawford and Seidel, 2013 operation costs

\section{Changes in regulations}

- Stricter environmental regulations (e.g., GHG reduction)

Agrawala et al., 2011

- Disaster management regulations

Damage to reputation of the company

- Decrease in customer satisfaction due to lower quality levels or delays in Agrawala et al., 2011 delivery of products due to other effects of climate change

Changes in energy consumption

- Changes in energy demand for cooling and heating process, transportation, Sussman and Freed, 2008; storage and office environments

OECD, 2015 

performance", International journal of Production Research, Accepted.

Performance measurement and management systems provide a wide range of advantages such as increased performance and competitive advantage, improved visibility on processes, standard framework for communication, tracking and documentation of performance among others (Bourne et al., 2000; Bititci et al., 2016).

Multiple performance indicators have been proposed and used both in the academic literature and industry. Gunasekaran and Kobu (2007), conducting a literature review on the performance measures in logistics and SC management, identify 27 key metrics for organisations. Some of these financial and nonfinancial metrics are as follows: return on investment, forecasting accuracy, labour efficiency, capacity utilisation, production flexibility, lead time, delivery reliability, value-added, perceived quality, etc. Various performance measurement models and frameworks have also been developed in the literature; e.g., balanced scorecard and supply chain operations reference (SCOR) model (Akyuz and Erkan, 2010; Bititci, 2015). Due to criticism of incomplete and incoherent performance metrics, the SCOR model was developed by the Supply Chain Council (SCC, 2012). The SCOR model provides a framework to describe and analyse all business processes in a standardised way across multiple industries. It provides a set of indicators to measure, monitor and benchmark the performance of specific process or the overall SC, based on five main performance attributes: reliability, responsiveness, agility, costs, and asset management (Sellitto et al., 2015).

A myriad of macro and micro risks affect the inputs, processes and outputs of organizations, damaging overall SC performance (Quang and Hara, 2018; Turken et al., 2020; González-Zapatero et al., 2020). However, there is a lack of conceptual models linking SC risk management and performance management domains.

\section{Research methodology}

This study uses a mixed methods approach to investigate the cascading effects of climate change risk on the performance of supply chains. As the research is trying to understand uncertain interactions between climate change and supply chains, a systems theory was identified to be suitable. Systems theory suggests that all phenomena can be viewed as a 'web of relationships' that have common patterns, behaviours, and properties like a 'system' ( 
Er-Kara, M., Ghadge, A. \& Bititci, US, (2020), "Modelling the impact of climate change risk on supply chain performance", International journal of Production Research, Accepted.

Sterman, 2000). The SD approach follows systems theory to model and simulate cause and effect relationships (Forrester, 1994; Sterman, 2000) and is found to be ideal for the nature of study undertaken here.

Following a mixed methodology approach, the study was conducted in three phases:

- Phase 1: A cognitive mapping approach utilised to present a holistic picture of interrelationships between climate change and SC performance management. Brainstorming sessions with subject experts were used to develop a mental model.

- Phase 2: A survey study to investigate awareness, perception, evaluations and experiences of 62 managers from different industries was used to determine the most prominent risks based on practitioner's point of view.

- Phase 3: Development of a $S D$ model to quantitatively analyse the impact of identified climate change factors on different SC indicators as well as overall SC efficiency and effectiveness following hypothetical case scenarios.

The three structured approaches guide towards achieving defined aim of the research. In the first phase, expert opinions were used to develop a cognitive map capturing interrelationships between the consequences of climate change and SC performance dimensions. The literature review on the impact of climate change on SC performance showed that climate change affects several entities and operations via myriad factors (Table 1). Unfortunately, there is no established methodology to apprehend these ambiguous interactions. Thus, we followed the cognitive mapping approach to capture complex interactions between different (internal and external) climate change factors and SC performance metrics. 'Cognitive map' is a visual representation of a mental model developed by an individual or group of experts for a given system capturing variables, entities and causal relationships based on available knowledge (Mital et al., 2018). Cognitive mapping has several advantages, such as the ability to model relationships that are very complex and not known with certainty; thus, providing the ability to combine expert knowledge and available information (Özesmi and Özesmi, 2004).

As observed in this cognitive map (Figure 1), several climate change factors influence SC performance indicators in multiple ways. Since it is not possible to model all climate change-related events/risks and their impact on SC performance dimensions during SD modelling, a second phase was introduced to carefully select only key climate-driven risks and 
Er-Kara, M., Ghadge, A. \& Bititci, US, (2020), "Modelling the impact of climate change risk on supply chain performance", International journal of Production Research, Accepted.

SC performance indicators. A survey-based study engaged with 62 managers to identify following:

- Impacted SC functions from the overall climate change threat

- Key climate change factors that impact SC operations

- Identification of critical SC performance dimensions capturing this impact

In the third phase, an SD model was developed to simulate and quantify the risk impacts on different SC performance indicators as well as overall SC efficiency and effectiveness.

The SD approach is based on systems theory and allows to analyse the dynamic behaviour of complex systems over time (Campuzano and Mula, 2011; Ghadge et al., 2013). The 'systems approach' is beneficial to model causal relationships and dependencies in order to simulate the overall system interaction (Bala et al., 2017). It is also used to identify policies or examine the effectiveness of decisions following simulation of the system. It is widely used for risk assessment comprising of different scenarios, due to its capability to simulate complex interactions and ability to perform sensitivity analysis (Li et al., 2016; Mehrjoo and Pasek, 2016; Olivares-Aguila and ElMaraghy, 2020). SD methodology follows logical modelling approach. First a causal loop diagram (CLD) is developed. CLD is a visual representation of the variables, links among variables, signs of the links and the feedback loops in a problem system. Next, stock-and-flow diagram capturing input, output and rate values are identified from the CLD. Mathematical equations and values are defined for input/output variables in this stage. After verification and validation of equations in the stock-and-flow diagram, the model is prepared for the simulation run with pre-defined input parameters (Rathore et al., 2020; Olivares-Aguila and ElMaraghy, 2020).

A traditional three-echelon SC network was modelled by considering material, cash and information flow under uncertain climatic conditions. As a part of the SD modelling approach, first, a causal loop diagram was drawn by incorporating the most prominent links between climate change-related risks and SC performance indicators, as revealed from the survey. After understanding the basic structural behaviour of the system, a stock and flow diagram was developed to model and analyse this problem in detail. A set of equations was assigned to describe these relationships. Model parameters and equations (Appendix A \& B) were identified based on expert knowledge, authors' experience and several logical assumptions due to lack of available and reliable historical data related to the impact of climate change on SC operations. The developed SD model was run to simulate nine case scenarios 
Er-Kara, M., Ghadge, A. \& Bititci, US, (2020), "Modelling the impact of climate change risk on supply chain performance", International journal of Production Research, Accepted.

representing three different risk exposure and vulnerability levels (high, moderate, low) for sourcing, manufacturing and delivery functions. The simulation model was developed and run in Vensim $^{\odot}$ - a commercial, discrete-event simulation platform.

\section{Analysis}

\subsection{Towards understanding the impact of climate change on supply chain performance}

The cognitive map shown in Figure 1 was developed based on two brainstorming sessions with subject experts to capture the links between climate change factors and SC performance. Five subject experts with academic background in supply chain risk management (2), performance measurement (1), climate change (1) and business management (1) identified potential interactions between climate change factors and key SC performance indicators during the first brainstorming session. In the second session, each expert developed their mental model and later discussed with other experts; before finalising the cognitive map capturing several interrelationships between climate change factors and SC performance holistically, as shown in Figure 1. Multiple influential variables from both domains were identified based the number of arrows directed to and from a variable capturing centrality/inter-dependence.

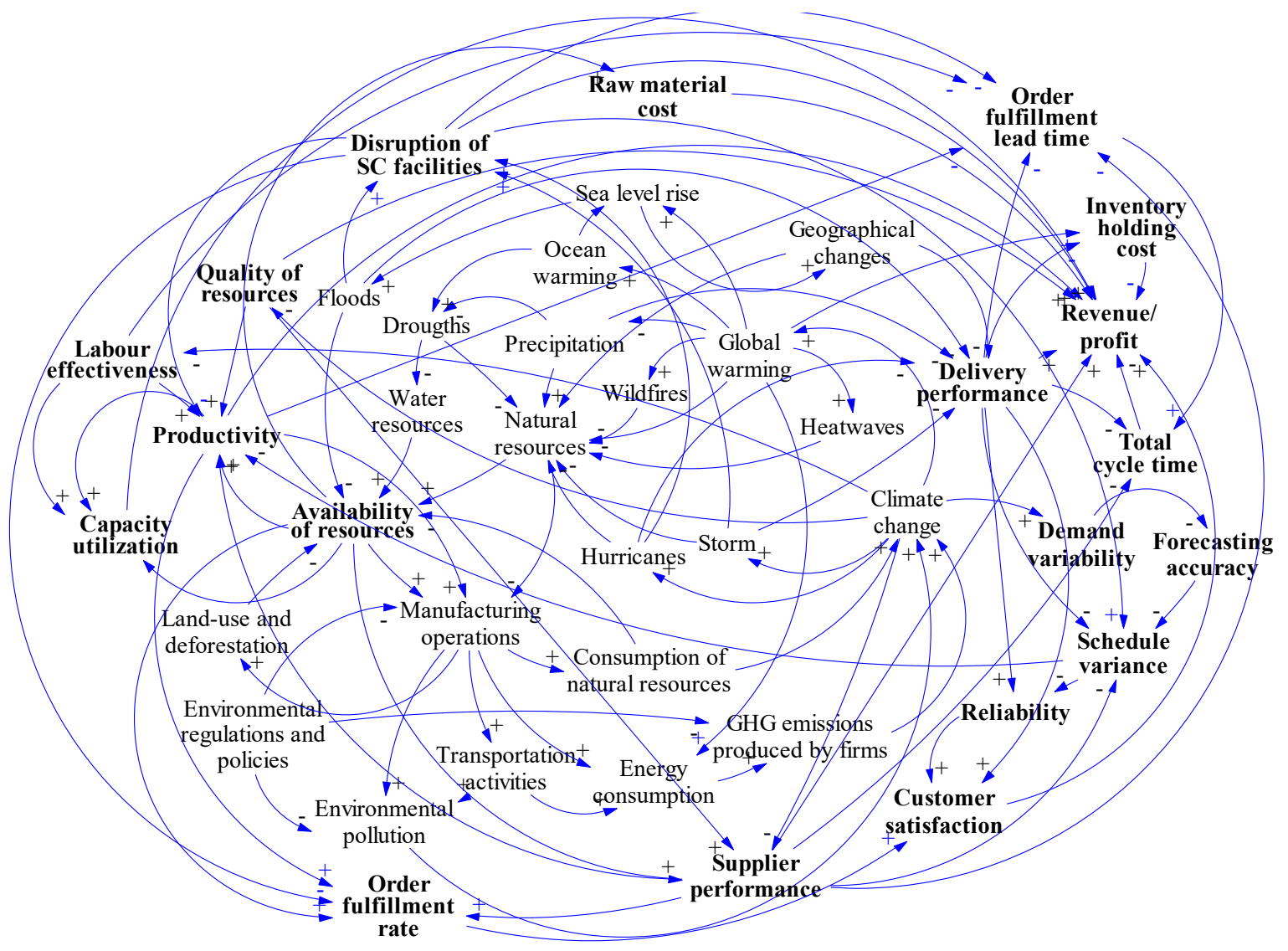


Er-Kara, M., Ghadge, A. \& Bititci, US, (2020), "Modelling the impact of climate change risk on supply chain performance", International journal of Production Research, Accepted.

Figure 1. Cognitive map for the interaction between climate change and SC performance

As observed in Figure 1, climate change leads to several environmental consequences including global warming and extreme weather events such as storms, hurricanes, etc. Especially, global warming affects a huge number of variables in the system; e.g., natural resources, heatwaves, sea level rise, precipitation and wildfire. These consequences may also impact and trigger other climate change risks via inherent complex relationships within the system. All of these consequences directly or indirectly affect different performance dimensions of SCs. As an example, global warming leads to an increase in ocean temperature, thus contributing to the melting of ice and the rising of sea levels. Climate change also disrupts the availability of natural resources via changes in precipitation level, droughts, and extreme weather events. Many resource-dependent industries are directly influenced by the scarcity and decreasing quality of raw materials. Changes in weather conditions, geographical changes and natural disasters caused by climate change may also lead to disruption in SC facilities, changes in labour effectiveness, variability in demand and decreases in delivery performance. These problems and increasing costs in supply chains proliferate along the network, leading to a decrease in productivity, profits and lead times and hence, order fulfilment. The unexpected ways in which climate change affects both the environment and organisational conditions lead to problems in planning and forecasting reliability. Figure 1 also captures the impact of industrial activities on climate change. Manufacturing operations require consumption of energy and natural resources, which may result in environmental degradation, loss of resource bases and GHG emissions. Both manufacturing operations and transportation activities are influenced by environmental pollution and changes in land use. Therefore, SC operations also contribute to the growth of existing climate change issues. Thus, environmental regulations and policies were incorporated for reducing the amount of waste and GHG emissions produced by SCs.

\subsection{Defining the boundaries of the model}

The cognitive map in the previous section provided a general picture of the SCs under influence of climate change factors. However, it is not possible to model all effects in a unique quantitative model. Therefore, a questionnaire was designed to identify the most prominent variables interlinking climate change and SC performance dimensions from an SC manager's perspective. To collect the survey data, first, introductory information was provided to respondents about the aim of the research. Survey questions focused on evaluation of the 
Er-Kara, M., Ghadge, A. \& Bititci, US, (2020), "Modelling the impact of climate change risk on supply chain performance", International journal of Production Research, Accepted.

criticality of different climate change factors and exposure of different SC functions to these risks.

The survey designed in the Qualtrics survey platform was shared with over 240 contacts in industry. Email and other social media platforms such as LinkedIn and Twitter were used to obtain responses. 62 responses (26\% response rate) were collected over five months (JanuaryMay 2019) from managers from multiple industries (e.g., food, textile, automotive, electronics, logistics, pharmaceutical, construction, machinery and energy). Targeted survey respondents were not limited to a specific industry, with a view of providing a general overview of climate change in the business world. Of the respondents, half were senior managers (i.e., directors and executives); $37 \%$ and $13 \%$ were at mid-level and junior managers, respectively. Average work experience of respondents was around 12 years. The 62 responses were checked for nonresponse bias by comparing early and late responses to reveal significant differences, if any (Armstrong and Overton, 1997; Blome et al., 2014). All the responses were divided into two groups based on their time of return and t-test was performed on two groups. The results of the two-samples revealed no statistically significant difference $(t=13.52, p>0.05)$ for all three aspects for which data was collected. The difference between the two groups for the categories was at the 5\% level. Thus, the sample was not found to have response bias and was used for the next level of analysis.

Unsurprisingly, $87 \%$ of the respondents stated that climate change is a significant risk for their SC/business, which indicates a high awareness of the climate change threat in industry. Respondents who did not think climate change poses a severe risk to their business were from the automotive, electronics and machinery industries. First, the respondents were asked to assess different climate change consequences based on the effect to their business based on a five-point scale (Don't know, No impact, Low impact, Moderate impact, High impact). Figure 2 shows the percentage of respondents providing the highest score for the negative effects of climate change factors on the overall performance of their SC network. Based on the responses, extreme weather events, temperature increase, deforestation and decrease in available land were selected as the primary external factors for the SD modelling. Changes in seasons was not included as temperature increase variability will indirectly include this effect. Detailed examination of the responses also revealed that, due to the direct and indirect relations between different climate change factors, the awareness and visibility of these links and their ripple effects are relatively low; e.g., differences between respondents' individual answers on rising 
Er-Kara, M., Ghadge, A. \& Bititci, US, (2020), "Modelling the impact of climate change risk on supply chain performance", International journal of Production Research, Accepted.

sea levels versus warmer oceans, and water resource problems versus deforestation due to high interaction between them.

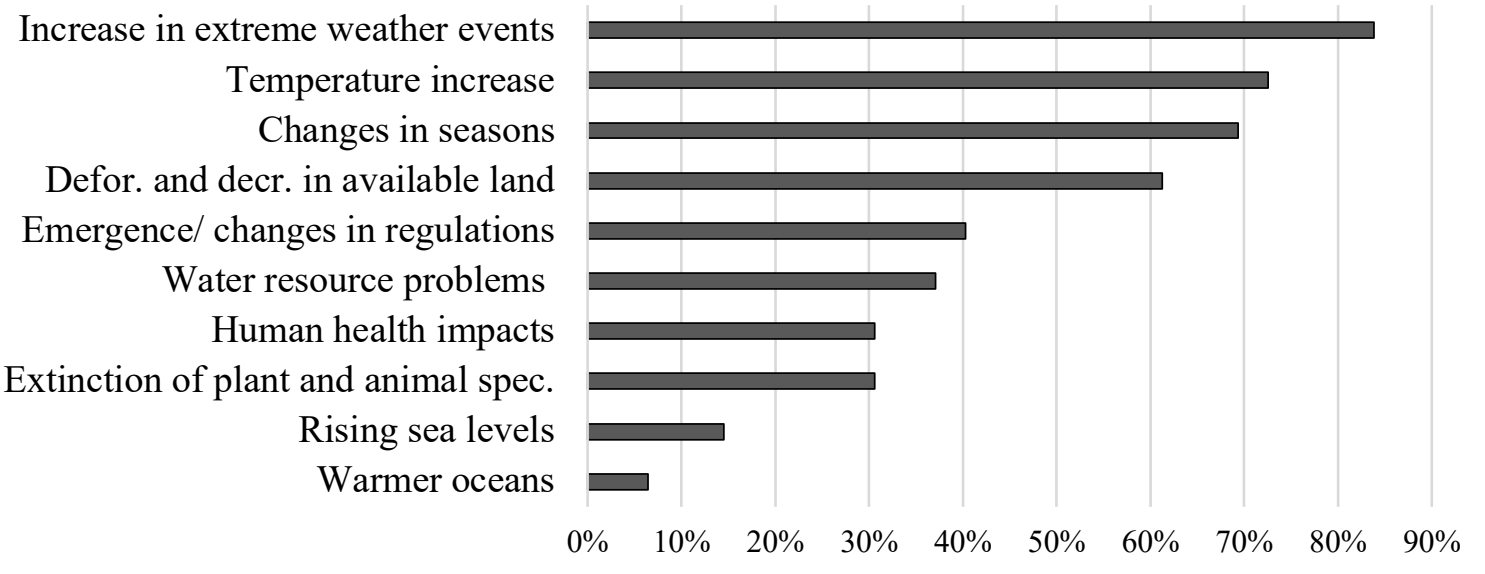

Figure 2. Response for most influential climate change factors

Secondly, respondents were asked to evaluate the climate change exposure level on ten SC/business functions. Figure 3 represents highly influenced SC functions. Supply, delivery, planning and forecasting, inventory management and manufacturing are the highest impacted functions due to climate change. Activities associated with planning and forecasting and inventory management overlap with supply and manufacturing function. Therefore, supply, manufacturing and delivery were selected as SC functions that would be most exposed to the negative effects of climate change driven-risks.

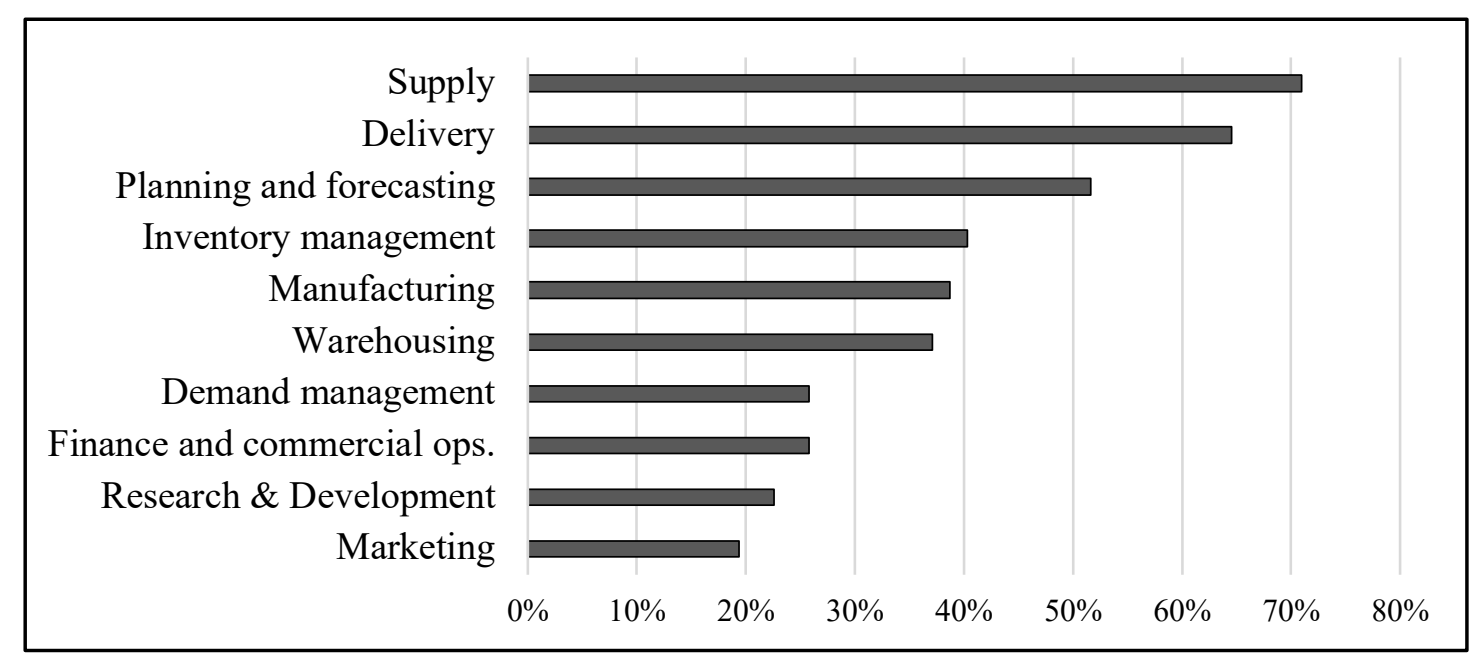

Figure 3. Response for most impacted SC functions due to climate change 

performance", International journal of Production Research, Accepted.

Respondents were also asked to assess the impact of each climate change factor/consequence on a more detailed set of performance dimensions. These performance dimensions namely, demand variability, availability of resources, raw material quality, raw material price, productivity, manufacturing lead time, manufacturing cost, product quality, warehousing/inventory holding cost, delivery lead time, delivery cost, maintenance cost, energy consumption and disruptions of SC facilities were identified. These results were complementary to most impacted SC functions as well as established SC performance measurement matrices. Survey results indicated that extreme weather events and temperature increase impact through non-availability and accessibility of resources, increase in raw material prices and disruptions to transportation routes, further cascading into reduced overall efficiency of SC operations.

\subsection{Developing system dynamics model}

The aim of this section is to develop the SD model of a three-echelon SC under the impact of critical climate change factors.

\section{Causal loop diagram}

Only the most prominent climate change factors and most vulnerable operations to climate change threat were identified for the development of the causal-loop model. Following the survey results, extreme weather events and temperature increase were identified as the major external factors for the SD model. These factors directly impact the availability of natural resources (e.g., crops, plants and animal species, water, fossil fuel reserves) due to decreased availability of land; further impacting the availability of raw materials in many natural resource-dependent industries. Secondly, the impact of extreme weather conditions on delivery performance was represented in two ways: decreased delivery speed and blockage of transportation routes due to extreme/adverse weather events (e.g., storms, snowfall). The causal loop diagram shown in Figure 4 represents the critical interactions between selected climate change factors and SC dynamics. Arrows represent the causal links between different elements of the system ("+": positive, "-": negative relationships).

As seen from Figure 4, climate change is an external factor of the system, and its consequences directly or indirectly affect several SC performance measures such as availability of raw materials, productivity, delivery performance, order-fulfilment rate and customer satisfaction. Besides the impact of climate change on physical flows in SC networks, 
Er-Kara, M., Ghadge, A. \& Bititci, US, (2020), "Modelling the impact of climate change risk on supply chain performance", International journal of Production Research, Accepted.

it also leads to some economic impact for SC stakeholders. The proposed model considers two types of costs that are impacted by the climate change; increasing raw material price due to growing resource scarcity problems and additional logistics costs because of delivery delays and blockage of transportation routes (e.g., higher carrying cost due to higher lead time, inventory holding cost during blockage). Efficiency and effectiveness dimensions are incorporated into the model to understand and evaluate the performance implications of climate change risk in SCs.

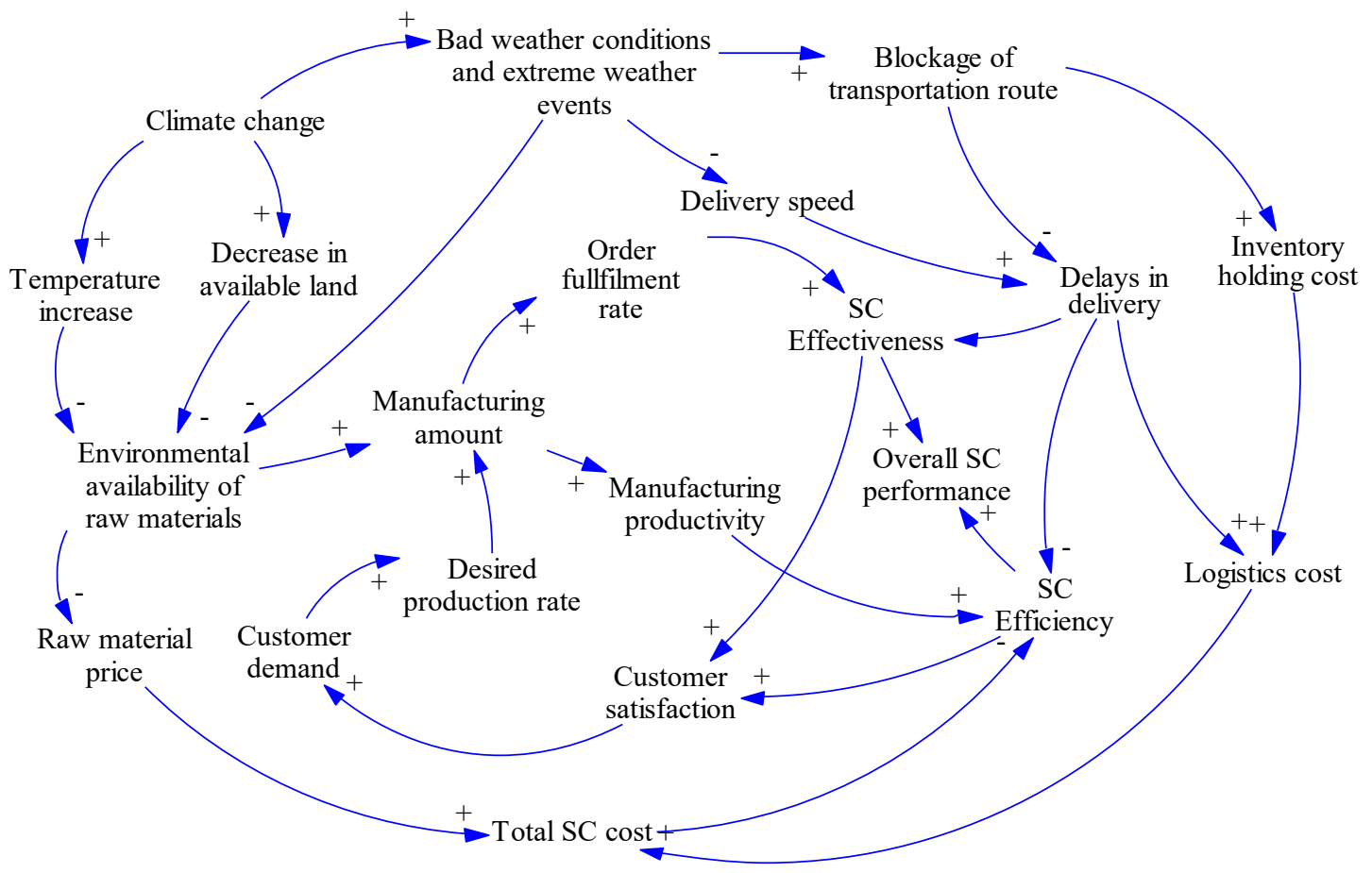

Figure 4. Causal loop diagram for the SD model

\section{Stock and flow diagram}

The developed causal loop diagram was later converted into a stock and flow diagram with multiple stock, flow and auxiliary variables. Figure 5 represents the stock and flow diagram of a three-echelon SC, including supply (sourcing/procurement) and manufacturing as key subsystems and delivery functions linked with the movement of goods between them. The objective of developing a stock and flow model was to assess changes in SC dynamics under varying climate change conditions. Here, input and output variables of the system were defined based on insights generated from the causal loop diagram. For more information regarding converting the causal loop diagram to a stock and flow diagram for obtaining simulation results in the SD, please refer to Forrester (1994) or Sterman (2000). 
Er-Kara, M., Ghadge, A. \& Bititci, US, (2020), "Modelling the impact of climate change risk on supply chain performance", International journal of Production Research, Accepted.

The SD model consisting of a stock and flow diagram was based on a continuous material flow throughout a three-echelon network. Due to lack of real-time data for simulation, hypothetical data with several parameter values and assumptions were considered. The quantity of monthly customer demand was assumed to be normally distributed with a mean of 1000 and a standard deviation of 100 . The model was designed such that, if the finished goods inventory is not sufficient to fulfil a customer order, the manufacturer will face stock-out issues. Initial inventory levels at supplier and manufacturer were set at 1200 to provide a steady state beginning for the simulation run.

Different scenarios were developed by varying climate change related disruption levels. Availability of raw materials, transportation blockage and bad weather-related delays were specified as random variables. Distribution parameters (e.g. mean, standard deviation, min, max) and parameter trend changes at different time steps were identified based on the characteristic of the scenario type. Since SD is a behaviour-oriented simulation approach, input values and input distributions require domain knowledge and experience (Ghadge et al., 2013). Hence, the parameter space was explored based on multiple runs with stochastic parameters. Parameter values and relative influence of each parameter on simulation behaviour were discussed with two industry practitioners to qualify the best numerical values for low (optimistic), moderate and high (pessimistic) conditions by referencing real world experiences and foresight. Other model parameters such as standard delivery time were determined by consulting experts about the most likely value. Appendix A and B provides detailed information on key variables, simulation parameters and scenario parameters used in this study.

Capturing impact of climate change risk effects on availability of raw materials and supply rate

Availability of resources is affected by disruption and found to be exponentially decreasing due to cascading impact (Ivanov et al., 2014; Ojha et al., 2018). Availability of raw materials was calculated with Equation (1).

Availability of raw materials

$$
=\text { Initial available resource value } * e^{\text {-combined climate effect } * \text { time }}
$$

Initial value of available resources was set at 1500 units ( $150 \%$ of mean demand). Combined climate effect showed that the level of climate change exposure is a function of the following variables: extreme weather events, temperature increase and decrease in available land. The value of these three variables was determined by assigning a severity value between 1 and 9. These variables have a different level of impact on the availability of resources. 


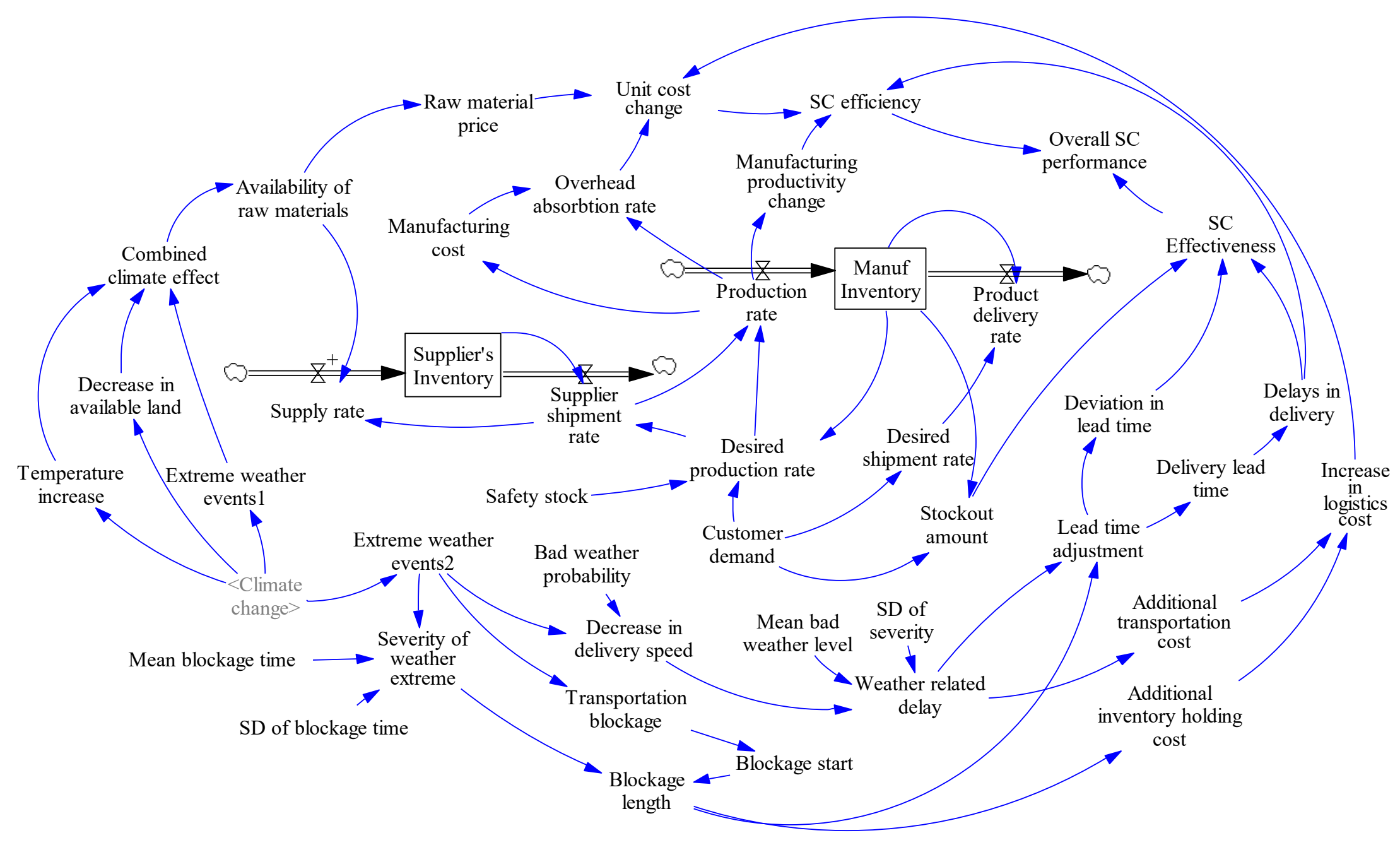

Figure 5. Stock and flow diagram of a supply chain under climate change 

performance", International journal of Production Research, Accepted.

Thus, different weights were assigned to each of these factors as $0.3,0.5$ and 0.2 , respectively. The combined climate effect variable was calculated by multiplying the weighted total with an adjustment coefficient to represent the real behaviour of the system following expert opinion (by examining what will happen under similar conditions in the real life). Raw material price was also set as a function of the availability of resources and the combined climate change impact (initial value=7.5 \$/unit).

\section{Capturing impact of weather conditions on logistics}

The initial value of the delivery lead time was set to seven days. Shipment of finished goods to customers may be delayed due to changes in weather patterns and extreme weather events in terms of increased lead time or may cause blockage of transportation infrastructure for a period. A lead time adjustment variable was added to represent these effects. Occurrence start time and severity of a possible transportation route blockage and weather-related delays were modelled as random variables. Mean, standard deviation and max distribution values were adjusted based on the state of climate change risk. In case of a route blockage or decrease in delivery speed (e.g. in case of heavy rain or storm), the additional time taken was addressed as a delay.

Table 2. Summary of scenarios

\begin{tabular}{ccccccc}
\hline \multirow{2}{*}{ Scenarios } & \multicolumn{5}{c}{ Effect of climate change on the supply chain } \\
\cline { 2 - 6 } & \multicolumn{4}{c}{ Availability of raw materials } & \multicolumn{3}{c}{ Logistics operations } \\
\hline L1L1 & $\checkmark$ & Moderate & High & Low & Moderate & High \\
\hline S1L2 & $\checkmark$ & & $\checkmark$ & & \\
S1L3 & $\checkmark$ & & & $\checkmark$ & \\
S2L1 & & $\checkmark$ & & & \\
S2L2 & & $\checkmark$ & & $\checkmark$ & \\
S2L3 & & $\checkmark$ & & & $\checkmark$ \\
S3L1 & & & & & & \\
S3L2 & & & $\checkmark$ & $\checkmark$ & $\checkmark$ & \\
S3L3 & & & $\checkmark$ & & & $\checkmark$ \\
\hline
\end{tabular}

The model included several performance indicators to analyse the behaviour of SC dynamics under varying climate change conditions, e.g., manufacturing productivity change, stock out amount, delays in delivery (logistics). Overall, system performance was calculated 
Er-Kara, M., Ghadge, A. \& Bititci, US, (2020), "Modelling the impact of climate change risk on supply chain performance", International journal of Production Research, Accepted.

based on the efficiency and effectiveness of the SC. SC efficiency was defined as a change function of unit cost and manufacturing productivity. SC effectiveness was calculated by stockout amount, deviation in lead time and delays in delivery. An empirical input validation process was performed to check how well the developed model corresponds to the reality (Rand and Rust, 2011). All key parameters were calibrated via running the model for different input values and analysing the behaviour of different system parameters with the help of SD expert and industry practitioners. Extreme values were tested to make sure the developed SD model works as expected. Finally, the model was accepted as representative of a traditional real-world SC network following the results of experiments conducted.

Availability of raw materials during supply and manufacturing activities was found to be a major bottleneck for the SC system identified earlier. Similar significant impact of climate change was observed on the logistical disruptions. For developing case scenarios presented in Table 2, this information was utilised along with considering three layers of severity (Low$30 \%$, Moderate- $60 \%$ \& High-90\%). For example, the S1L2 disruption scenario represents the low availability of raw materials with a moderate level of logistical operations for climate change uncertainty. The physical meaning of this scenario is that there is only $30 \%$ availability of raw materials at the supplier/manufacturer, along with $60 \%$ available capacity of logistics. The simulation model was run for a 40 -year horizon, as the accuracy of the predictions will be inaccurate beyond this time interval due to high uncertainty concerning climate change.

\section{Simulation and findings}

By simulating the developed SD model, the following results were obtained. Figure 6(a) shows the expected decrease in availability of raw materials due to the combined impact of climate change risk on natural resources and associated ecosystems for three groups of scenarios. An adjustment coefficient that was included in the combined climate effect formulation was varied to develop three scenario groups with different severity levels as low, moderate and high. The percentage decreases in the availability of raw materials were observed to be $40 \%, 53 \%$ and $78 \%$ for low, moderate and high impact scenarios, respectively. It is evident from Figure 6(a) that, if SCs and governments do not take action to reduce climate change and associated risks, the worst scenario shows that some raw materials (e.g., crops, minerals) may expeditiously decrease and SCs may be obliged to find alternative resources. 
Er-Kara, M., Ghadge, A. \& Bititci, US, (2020), "Modelling the impact of climate change risk on supply chain performance", International journal of Production Research, Accepted.

In this study, demand was assumed to be normally distributed. However, when the simulated impact is combined with other external factors such as growing global population and use of natural resources, the uncontrolled effects of climate change will be much more intense for agriculture, forestry, mining and bioenergy sectors.

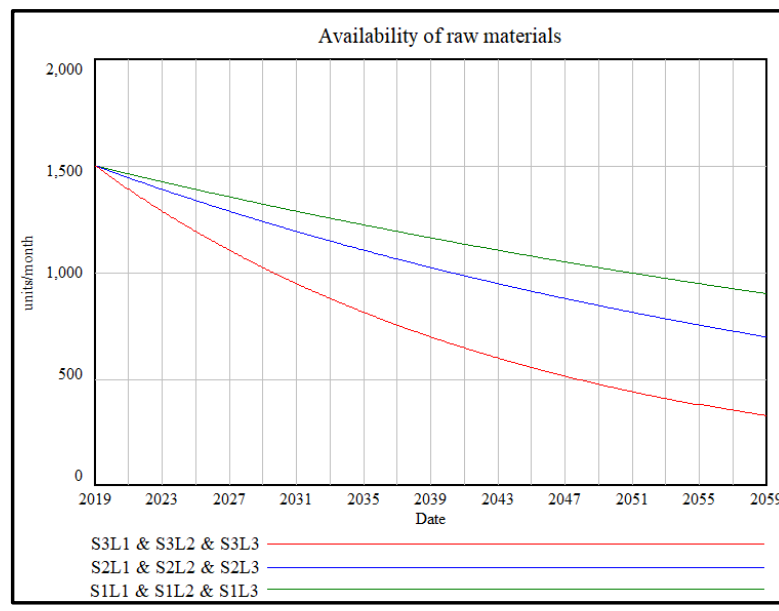

(a)

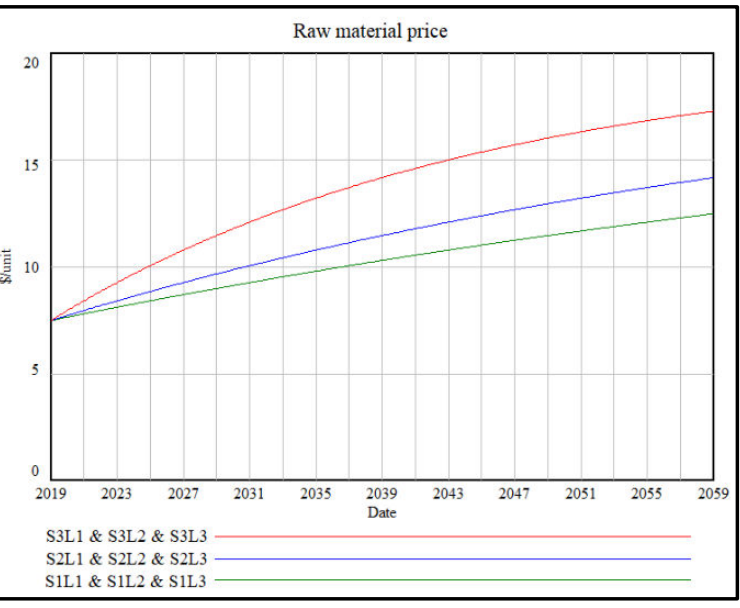

(b)

Figure 6. Changes in available resources and raw material price due to combined climate change impact

Problems associated with the availability and accessibility in raw materials were directly reflected in the commodity prices. Figure 6(b) shows an increase in unit raw material price due to supply problems resulting from combined climatic impact. The percentage increases in unit price were approximately $66 \%, 89 \%$, and $130 \%$ for low, moderate and high impact on resources, respectively. Rising raw material prices and decline in the raw material market size puts pressure on manufacturing costs, productivity, product price and revenue. For perishable/time-sensitive products, the distribution and storage of raw materials should also be considered, as they bear extra cost and energy consumption. Although this was not considered in the model, with increasing global temperatures, the energy consumption of refrigerator systems in delivery and warehousing is expected to grow exponentially.

Figure 7 represents the decrease in production rate and the increasing stock-out amount due to supply problems resulting from the adverse impact of climate change risks. Supply shortages and increases in raw material prices have a significant impact on manufacturing productivity. Therefore, downward trends in productivity and manufacturing capacity should be assessed along with other economic impacts of climate change. 
Er-Kara, M., Ghadge, A. \& Bititci, US, (2020), "Modelling the impact of climate change risk on supply chain performance", International journal of Production Research, Accepted.

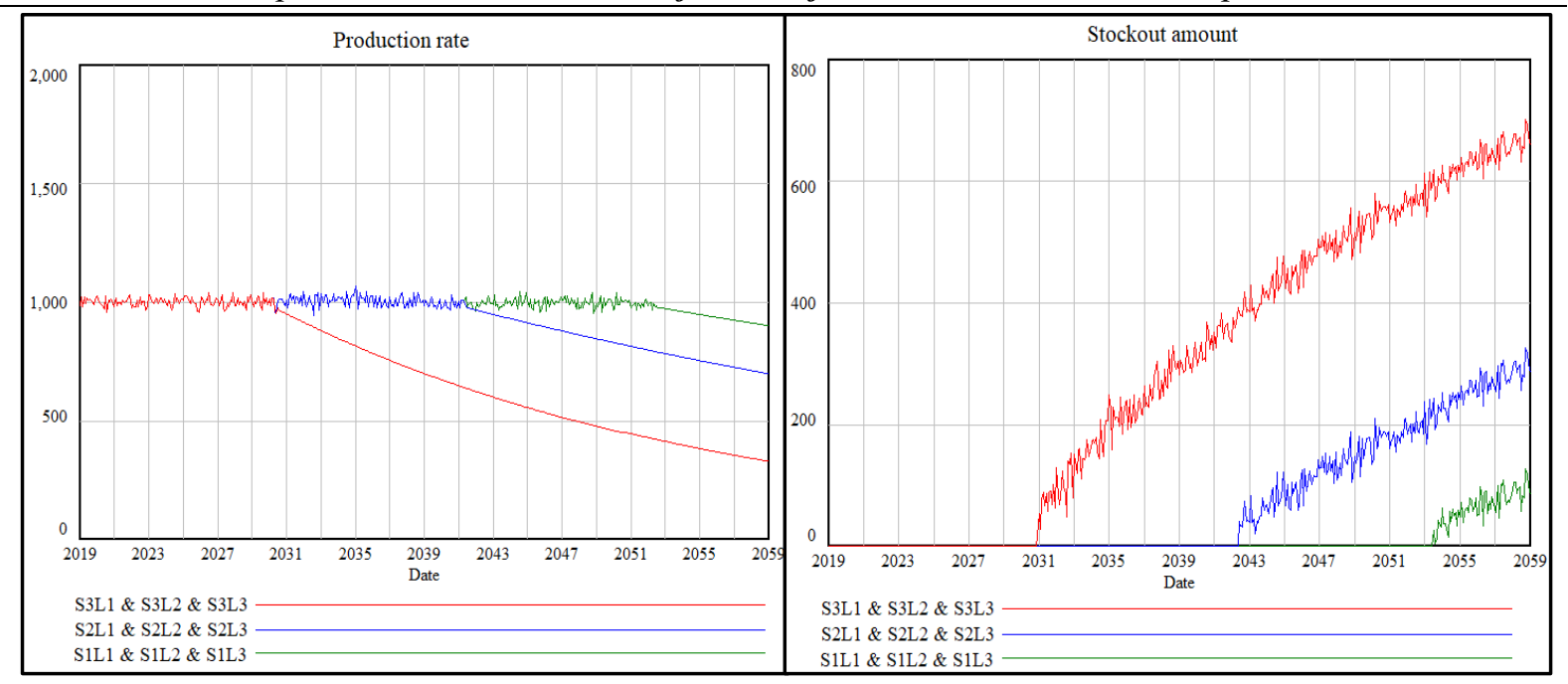

Figure 7. Changes in production rate and stock-out amount due to climate change

Figure 8 represents delay in delivery as a percentage of standard delivery lead time and increase in total logistics costs as a percentage of initial standard value. These figures were generated based on simulation of bad weather conditions and extreme weather events. As seen in the Figure 8, frequency, severity and duration of both events are observed to be increasing.

All modes of transportation are increasingly affected by adverse weather conditions and extreme weather events based on time, volatility and costs of operations. It is expected that delivery performance and reliability will increase to a critical level within 40 years. This may cause scheduling problems across the whole SC network. Increased lead time and keeping products on hand during transportation blockages bear additional transportation, labour and inventory holding costs.

The effects of disruption may quickly propagate throughout the whole SC network (Ghadge et al., 2012; Scheibe and Blackhurst, 2018; Dolgui et al., 2018; Dolgui et al., 2020); therefore, the proposed SD model considered the impact of various climate change factors on different SC performance indicators. These impacts were combined and examined under two main dimensions - efficiency and effectiveness; as an SC may be ineffective even though they are efficient. Figures 9 and 10 show the changes in these variables for all the scenarios considered in this study (initial condition $=100 \%$ for both variables). It was observed that the average decrease in the operational efficiency of the SC was higher than effectiveness in all scenarios. A relatively higher decrease in efficiency (compared to effectiveness) is driven by a significant decrease in resources to fulfil growing SC demand. Decreases in both SC efficiency and effectiveness leads to a decline in the overall SC performance. 
Er-Kara, M., Ghadge, A. \& Bititci, US, (2020), "Modelling the impact of climate change risk on supply chain performance”, International journal of Production Research, Accepted.

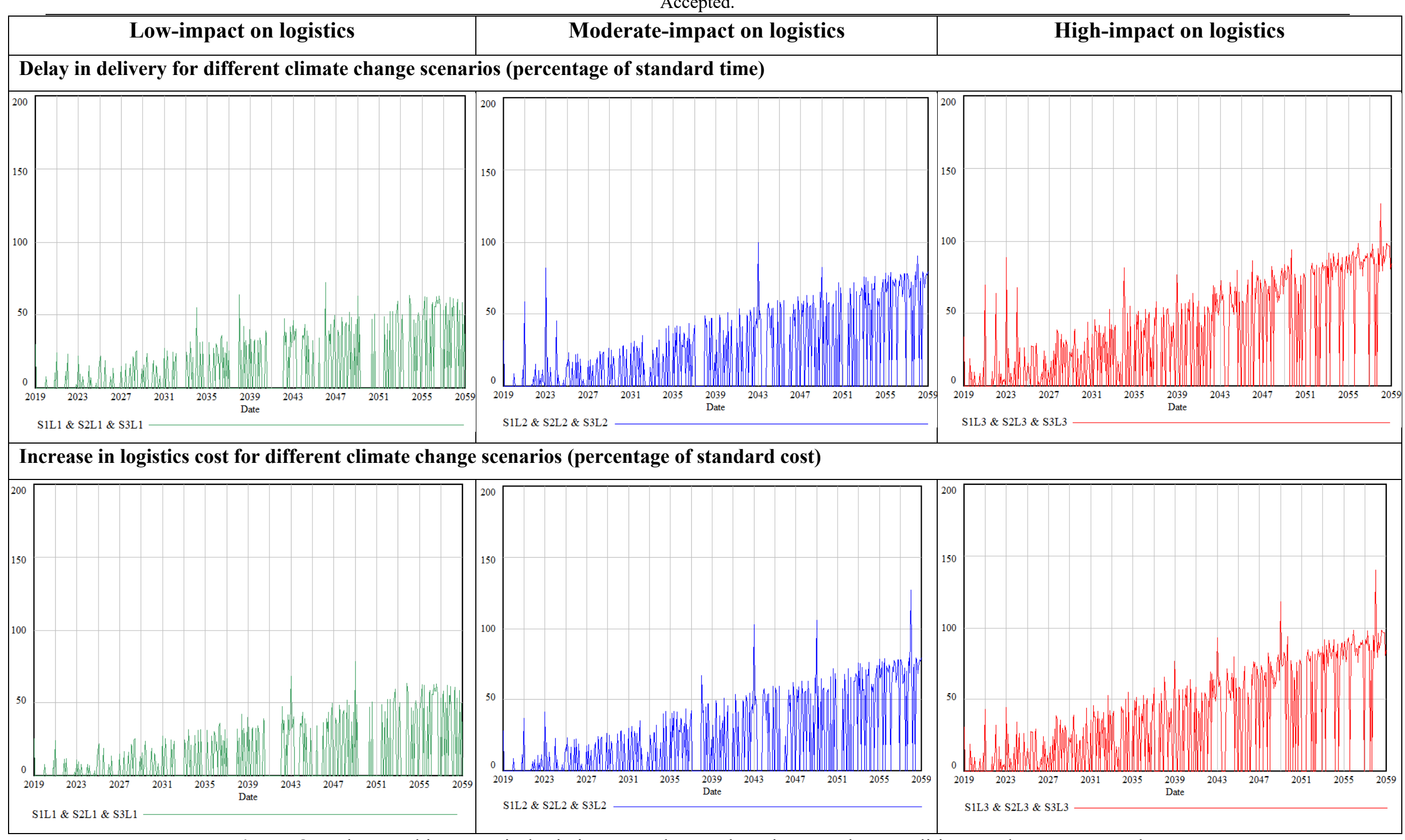

Figure 8. Delays and increase in logistics costs due to changing weather conditions and extreme weather 


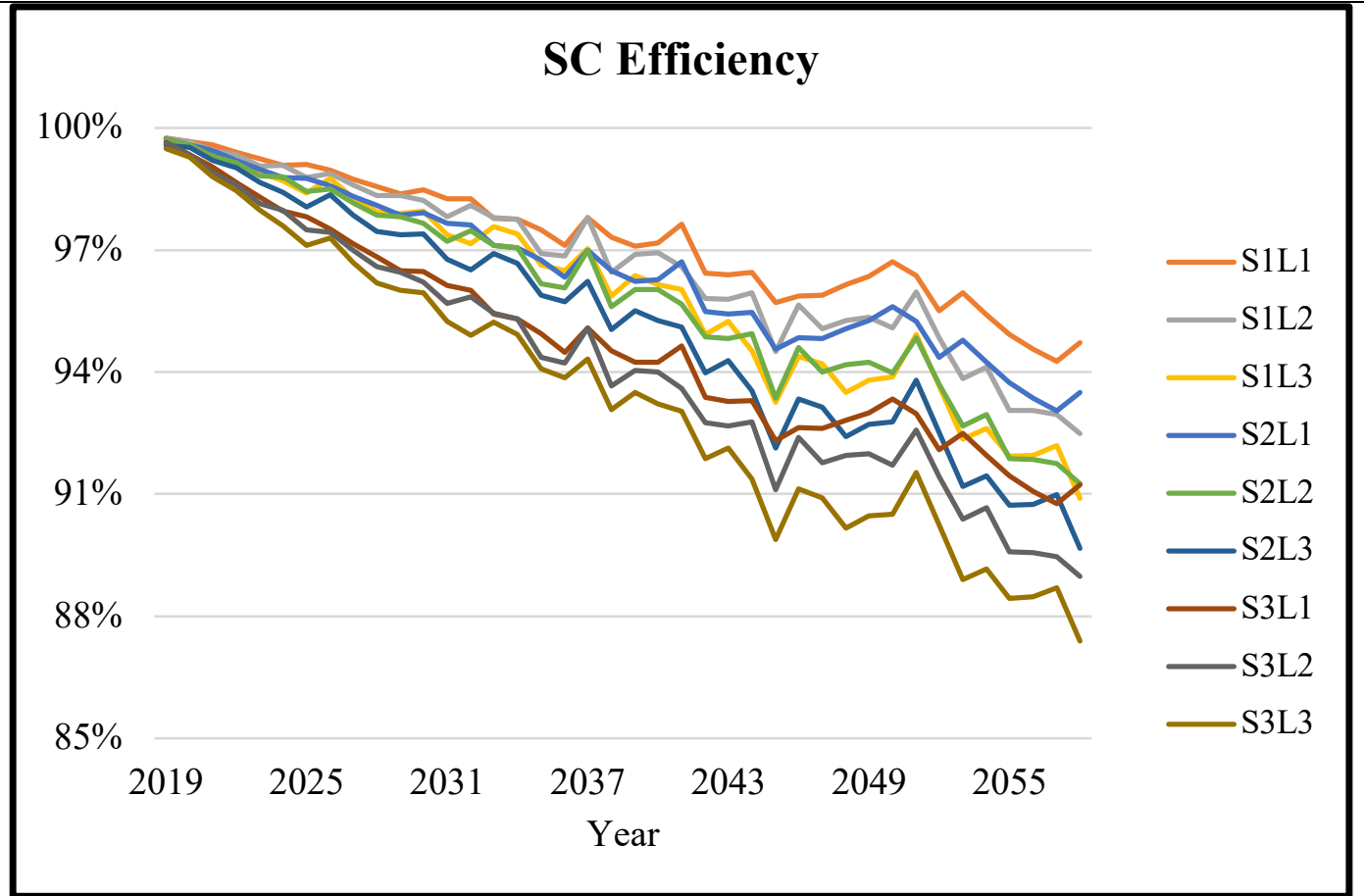

Figure 9. Changes in SC efficiency for different climate change scenarios

Figure 11 shows the box plot for the comparison of nine scenarios based on changes in the overall SC performance. Especially, the SCs, of which both supply and delivery functions are highly affected and are under severe threat due to climate change. SC performance in Scenario S3L3 decreased to $79 \%$ in 40 years. In the best case (Scenario S1L1), the expected performance level was around $92 \%$.

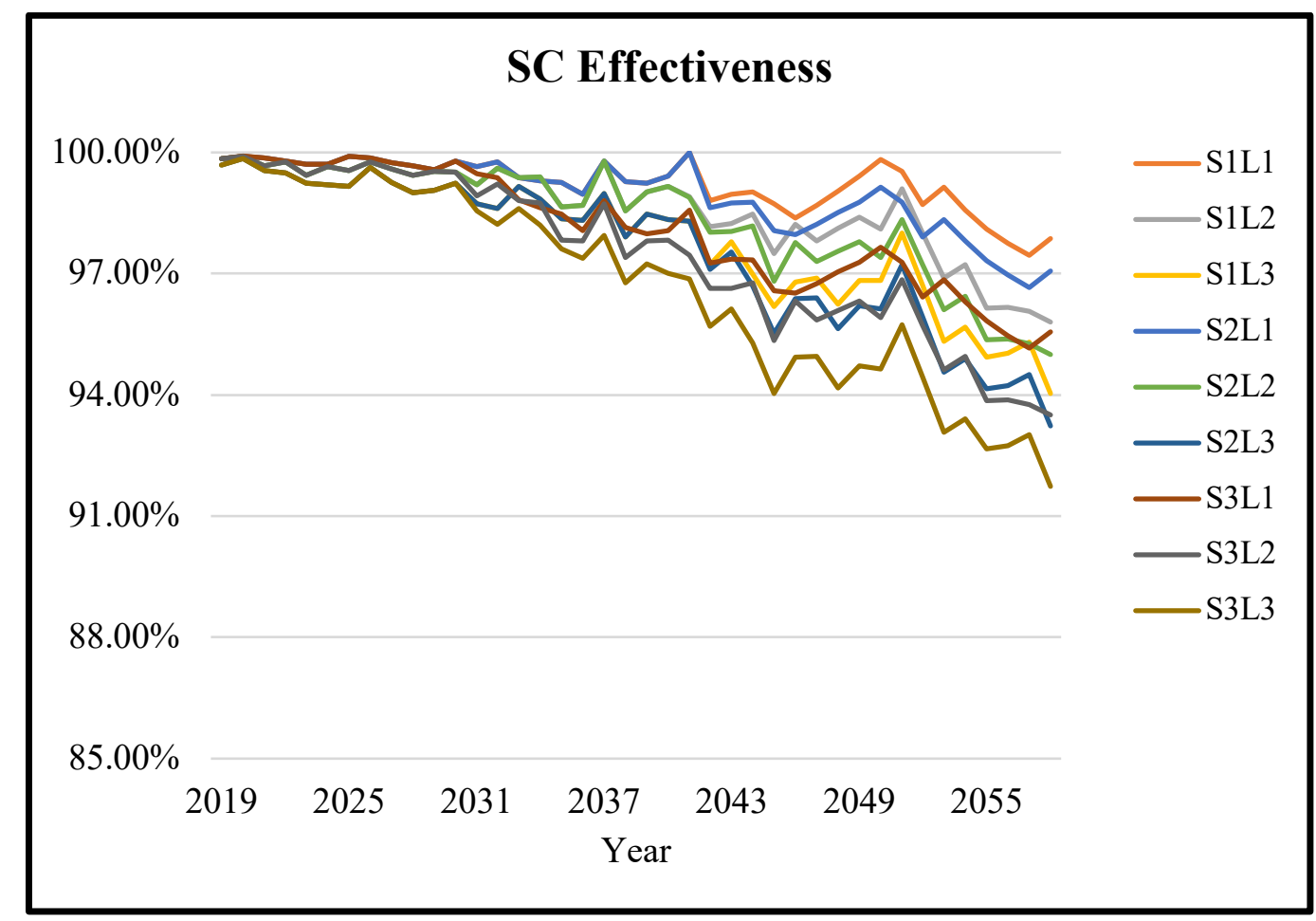

Figure 10. Changes in SC effectiveness for different climate change scenarios 


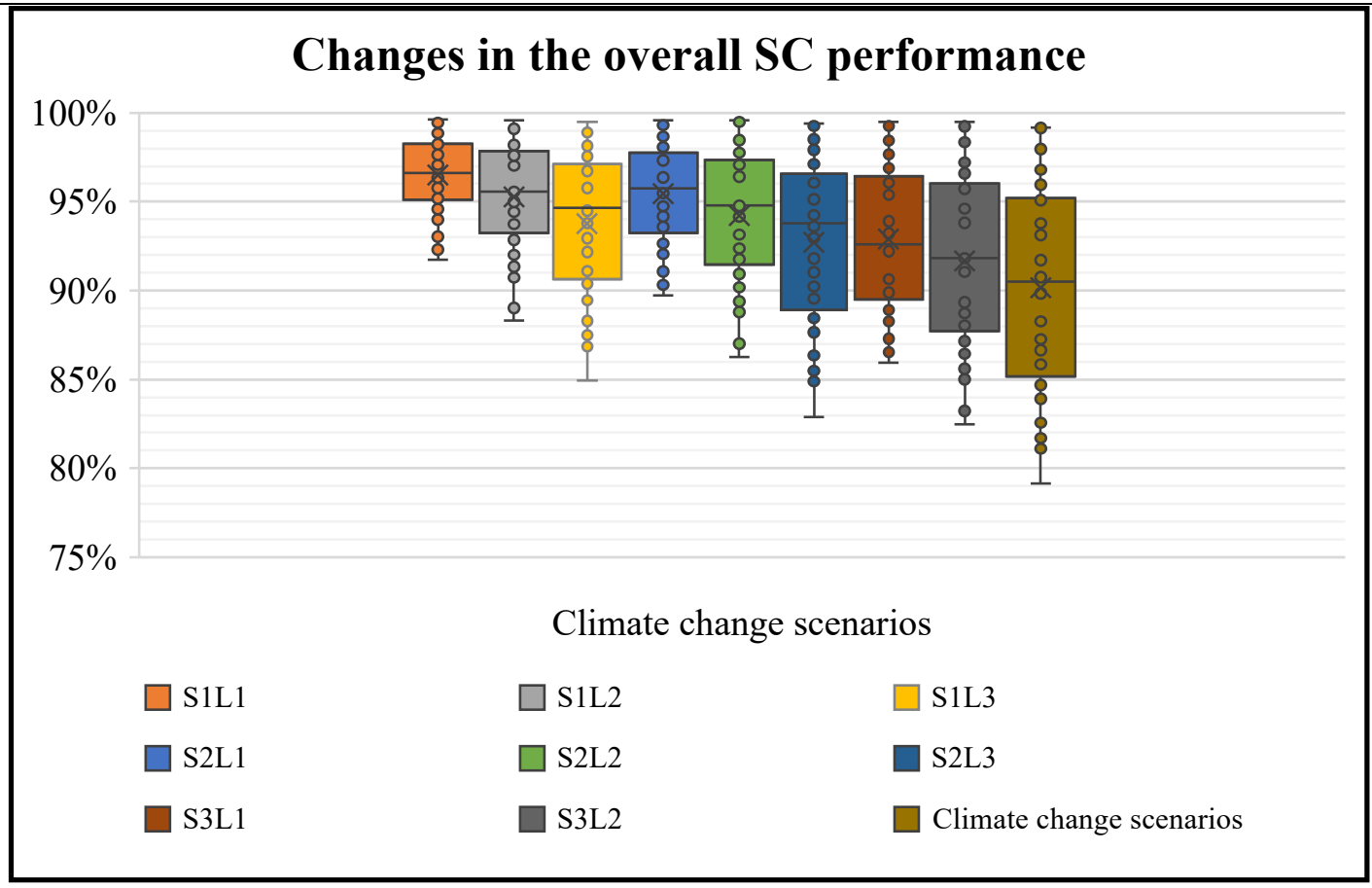

Figure 11. Comparison of changes in the overall SC performance under different scenarios

The results of the proposed SD simulation model provided a platform for quantifying and understanding interactions between climate change risks and SC performance.

\section{Discussion and theoretical implications}

The developed SD model provides information on the links between climate change-related risks and SC operations. The following prepositions can be put forward for this interaction based on the results of study. Implications and suggestions are also provided for an effective response under each proposition.

\section{Proposition 1: There is a complex and strong interaction between climate change factors and SC performance dimensions.}

This study empirically reveals a high-level dynamic interaction between climate change factors and SC performance indicators. Therefore, in our view, these two fields should be assessed together by businesses, governments, agencies and organisations to better manage and respond to disruptions. Practitioners and academics seem more aware of the direct and immediate impact of climate change risk, and indirect impacts are generally neglected: e.g., long-term 
Er-Kara, M., Ghadge, A. \& Bititci, US, (2020), "Modelling the impact of climate change risk on supply chain performance", International journal of Production Research, Accepted.

availability of resources. The proposed systems theory-based approach put forward the multidimensional direct and indirect impact of climate change both in the short- and long-term.

Preposition 2: When the impact of climate change is examined at the SC level, the cascading effect of these risks, along with overall SC performance, efficiency and effectiveness become more apparent.

The survey shows that businesses are already feeling the effects of climate change in their operations. However, the propagation of the combined climatic effects along the entire SC remains overlooked. SC ecosystems are composed of multiple, complex and connected entities, layers and activities, which make these networks inherently vulnerable to the propagative and cascading effects of potential risks (Ghadge et al., 2020). The proposed SD analysis provides insights into how the impacts of different climatic risks on different levels of an SC propagate along the network and how this combined climate change effect is observed on overall SC performance, efficiency and effectiveness.

The results of the model demonstrate the need for substantial intervention for holistic, network-level approaches for climate change risk management systems. It should also be noted that companies may be more susceptible to climate change-related risks via unprepared and weak stakeholders, e.g., suppliers. Notably, global SC networks need to assess geographical disparities in exposure to climate change carefully. Increased information sharing, visibility, communication and reporting about climate change are some strategies that may increase climate change resilience and adaption capabilities.

Proposition 3: There is a remarkable difference among the awareness level (and assessments of climate change risk factors) of managers from different sectors.

Despite there being a common view concerning the growing danger of some climatic risks (e.g., weather extremes), a significant difference is observed among managers' responses on the assessment of the interdependency between particular climate change factors and performance dimensions. This was an expected case as the target group was not restricted to a specific industry, and the exposure and vulnerability of each organisation is highly dependent on the industrial sector, geographical region and business network structure. Some sectors are inherently more vulnerable to the climate change threat, e.g., agriculture, food and renewable energy. However, the results reveal that climate change risk is 'highly underrated', and 
Er-Kara, M., Ghadge, A. \& Bititci, US, (2020), "Modelling the impact of climate change risk on supply chain performance", International journal of Production Research, Accepted.

awareness and visibility regarding the links between climate change factors and their "ripple effects' are generally overlooked.

Organisations' business model/strategies and performance management systems should cover climate change threat to survive in today's rapidly changing and volatile climate. Both climate change science and SC networks inherently cover myriad uncertainties and complex relationships; therefore, there may be sudden and unpredicted changes in the system. Especially, changing patterns of extreme events and natural disasters are increasingly linked to climate change and associated risks. Hence, adaptability and disaster recovery planning are of vital importance while facing climate change risk.

\section{Conclusion}

Following a systems perspective, this study conceptualised the interaction between climate change risk and SC performance for assessing the impact of one over other. The study consisted of three main phases. First, a group of experts identified potential impacts of climate change on SCs following development of a cognitive map (Figure 1). Later, a survey was applied to a group of practitioners to filter key climate change factors and their impact on major SC performance dimensions. It was observed that sourcing, manufacturing and logistics are the most vulnerable SC operations to climate change due to the combined impact of temperature increase, decrease in available land and extreme weather events on the availability of raw materials and resource capacity. Following the survey, in the third phase, an SD model was developed to simulate these prominent relations and their impact on overall SC performance, efficiency and effectiveness. The impact of climate change-driven risks was simulated under three levels (low, moderate, and high) for both the availability of resources and delivery performance, resulting in nine different hypothetical case scenarios. The study quantified the impact of climate change risk on SC performance.

Climate change risk has started to transform business; however, academia has lagged behind these developments compared to the industry. The academic literature is dominated with research on environmentally friendly technologies and risk mitigation strategies; the opposite perspective, the impact of climate change on business, remains highly undervalued and underestimated. Need for empirical research to model, quantify and predict the impact of climate change-driven risks on SCs (Ghadge et al., 2020) was an evident research gap. This 
Er-Kara, M., Ghadge, A. \& Bititci, US, (2020), "Modelling the impact of climate change risk on supply chain performance", International journal of Production Research, Accepted.

study is believed to bridge the gap through the integration of supply chain risk management and performance management concepts. Limited number of studies have focussed on the integration of risk management and performance measurement within supply chain context (e.g. Kache and Seuring, 2014; Chaudhuri et al., 2020). This study reveals the importance of incorporating risk management into organization's list of performance measures for effective supply chain management. This helps organizations as well as SCs to be better prepared for uncertain crises or disruptions.

This study contributes to the literature in three key dimensions. First, this study conceptualises and investigates the uncertain interaction between climate change and SC performance based on a review of relevant literature and the development of a cognitive map. The originality of this research resides in bringing together climate change inputs and behaviour of SC dynamics within an SC performance measurement perspective. The proposed systems approach-based structure offers a deeper understanding and holistic picture of the relationship between climate change factors and SC performance dimensions. Second, it provides an SD-based model to quantify the implications of climate change risk on supply chain performance, efficiency and effectiveness. Such quantitative analysis facilitates and enhances our knowledge and understanding of the cascading propagation mechanism of climate change risk across supply chain networks. A systems theory approach helps to improve the visibility of climate change-related risks and SD methodology provides a platform to investigate the changes in performance under changing climatic conditions. Third, although there is a growing awareness of the impact on climate change and global warming on business operations, its generalisability for overall SC performance has not been addressed in the literature. To the best of the authors' knowledge, this study is novel by providing a comprehensive, quantitative, systems theory-based assessment for capturing interrelationship between two key mutually-influencing areas. The authors expect this article to be a steppingstone for further research and providing a new perspective for performance management in developing climate-smart and adaptable SCs.

The study also provides a few propositions and managerial implications. First, insights generated on the most influential climate change factors and most influenced SC functions will help SC managers to better plan for climate change risk management. Assessment results show the extent of implications on key SC performance matrices. This information is vital for performance measurement and management. Furthermore, 'closed-loop' causal relationship 
Er-Kara, M., Ghadge, A. \& Bititci, US, (2020), "Modelling the impact of climate change risk on supply chain performance", International journal of Production Research, Accepted.

evidenced between climate change and supply chain will encourage practitioners to be more considerate towards the environment. This systems-theory driven holistic study is expected to encourage SCs/businesses in making proactive investments in order to mitigate climate-change related future disruptions.

The study has some limitations. The relationship between climate change and SC performance is multi-fold and covers a wide range of factors that increase the complexity of the problem. Future study can explore this intricate relationship following a micro-level analysis. It should also be noted that, scientific evidence shows that climate change is accelerating fast; hence, firms must develop robust assessment capabilities to manage this inevitable risk better. Taking a clue from this study, similar empirical and quantitative studies on climate change should be undertaken to develop comprehensive understanding of cascading effect on wider supply chain ecosystem. Future studies should also focus on developing robust risk mitigation strategies to quickly reduce and possibly overcome the impact of climate risk on global supply chains. Each business within network needs to build resilience to the growing climate change risk and its cascading impact on the wider SC network (Ivanov et al., 2017; Dolgui et al., 2018). Although the SD model has some limitations and assumptions in terms of the boundaries of the model and included variables; the results of the study are presented by considering the current state of the global markets and different sectoral characteristics to overcome some of these weaknesses. In the simulation model, the scope of climate change impact was limited only to factors and interrelationships identified in the survey. Another major limitation of the study is the difficulty to gather and utilise historical data on the impact of climate change on SC operations, as quantification of this relationship is complex and equally difficult. Additional data from different sources (e.g. meteorological data) could be used in future studies to better understand the implications of climate risk on supply chain performance. Despite the above limitations, this study helps to model complicated relationships and thus improve the understanding of the effects of climate change risk on overall SC performance.

Acknowledgement: This study was supported by the Scientific and Technological Research Council of Turkey (TUBITAK) under the TUBITAK BIDEB 2219-International Postdoctoral Research Scholarship Programme. Authors would also like to thank reviewers and special issue guest editor for their constructive recommendations for improving the quality of manuscript. 

performance", International journal of Production Research, Accepted.

\section{References}

Agrawala, S., Carraro, M., Kingsmill, N., Lanzi, E., Mullan, M., Prudent-Richard, G. 2011. Private Sector Engagement in Adaptation to Climate Change: Approaches to Managing Climate Risks. OECD Environment Working Papers, No. 39, OECD Publishing.

Akyuz, G.A., and Erkan, T.E. 2010. "Supply chain performance measurement: a literature review." International Journal of Production Research 48 (17): 5137-5155.

Alves, M.W.F.M., Jabbour, A.B.L.S., Kannan, D., Jabbour, C.J.C. 2017. "Contingency theory, climate change, and low-carbon operations management." Supply Chain Management: An International Journal 22 (3): 223-236.

Andreoni, V., and Miola, A. 2014. Climate Vulnerability of the Supply-Chain: Literature and Methodological review. Luxembourg: Publications Office of the European Union.

Armstrong, J.S., Overton, T.S. 1997. "Estimating nonresponse bias in mail surveys." Journal of marketing research 396-402.

Bala, B.K., Arshad, F.M., and Noh, K.M. 2017. System Dynamics: Modelling and Simulation. Springer: Singapore.

Bergmann, A., Stechemesser, K., and Guenther, E. 2016. "Natural resource dependence theory: Impacts of extreme weather events on organizations." Journal of Business Research 69: 1361-1366.

Bititci, U. 2015. Managing Business Performance: The Science and the Art. John Wiley \& Sons.

Bititci, U., Cocca, P., and Ates, A. 2016. "Impact of visual performance management systems on the performance management practices of organisations." International Journal of Production Research 54 (6): 1571-1593.

Blome, C., Schoenherr, T., and Eckstein, D. 2014. "The impact of knowledge transfer and complexity on supply chain flexibility: A knowledge-based view." International Journal of Production Economics 147: 307-316.

Bourne, M., Melnyk, S., and Bititci, U. S. 2018. "Performance measurement and management: theory and practice." International Journal of Operations \& Production Management 38 (11): 2010-2021.

Bourne, M., Mills, J., Wilcox, M., Neely, A., Platts, K. 2000. "Designing, implementing and updating performance measurement systems." International Journal of Operations \& Production Management 20 (7): 754-771.

Campuzano, F., and Mula, J. 2011. Supply Chain Simulation: A System Dynamics Approach for Improving Performance. Springer-Verlag, London.

Chaudhuri, A., Ghadge, A., Gaudenzi, B., Dani, S. 2020. "A conceptual framework for improving effectiveness of risk management in supply networks". International Journal of Logistics Management, 31 (1): 77-98.

Crawford, M., and Seidel, S. 2013. Weathering the storm: building business resilience to climate change. Center for Climate and Energy Solutions, Arlington. Accessed 30 July 2019. https://www.c2es.org/site/assets/uploads/2013/07/weathering-the-storm-fullreport.pdf

Dahlmann, F., and Roehrich, J.K. 2019. "Sustainable supply chain management and partner engagement to manage climate change information." Business Strategy and the Environment 28 (8): 1632-1647.

Dolgui, A., Ivanov, D., \& Sokolov, B. 2018. Ripple effect in the supply chain: an analysis and recent literature. International Journal of Production Research 56(1-2): 414-430.

Dolgui, A., Ivanov, D. and Rozhkov, M. 2020. "Does the Ripple Effect Influence the Bullwhip Effect? An Integrated Analysis of Structural and Operational Dynamics in the Supply Chain.” International Journal of Production Research 58 (5):1285-1301. 
Er-Kara, M., Ghadge, A. \& Bititci, US, (2020), "Modelling the impact of climate change risk on supply chain performance", International journal of Production Research, Accepted.

Fleming, A., Hobday, A.J., Farmery, A., van Putten, E.I., Pecl, G.T., Green, B.S., LimCamacho, L. 2014. "Climate change risks and adaptation options across Australian seafood supply chains - A preliminary assessment." Climate Risk Management 1: 3950.

Forrester, J. W. 1994. "System dynamics, systems thinking, and soft OR.” System dynamics review 10 (2-3): 245-256.

Gasbarro, F., Iraldo, F., and Daddi, T. 2017. "The drivers of multinational enterprises' climate change strategies: A quantitative study on climate-related risks and opportunities." Journal of Cleaner Production 160: 8-26.

Ghadge, A., Dani, S. and Kalawsky, R. 2012. Supply chain risk management: present and future scope. International journal of logistics management, 23(3): 313-339.

Ghadge, A., Dani, S., Chester, M., Kalawsky, R. 2013. "A systems approach for modelling supply chain risks." Supply chain management: an international journal 18(5), 523-538.

Ghadge, A., Wurtmann, H., and Seuring, S. 2020. "Managing climate change risks in global supply chains: a review and research agenda." International Journal of Production Research 58(1): 44-64.

González-Zapatero, C., González-Benito, J., Lannelongue, G., Ferreira, L.M. 2020. "Using fit perspectives to explain supply chain risk management efficacy." International Journal of Production Research, Online.

Gunasekaran, A., and Kobu, B. 2007. "Performance measures and metrics in logistics and supply chain management: a review of recent literature (1995-2004) for research and applications." International Journal of Production Research 45 (12): 2819-2840.

IPCC 2014. Climate Change 2014: Mitigation of Climate Change. Contribution of Working Group III to the Fifth Assessment Report of the Intergovernmental Panel on Climate Change [O. Edenhofer, R. Pichs-Madruga, Y. Sokona, E. Farahani, S. Kadner, K. Seyboth, A. Adler, I. Baum, S. Brunner, P. Eickemeier, B. Kriemann, J. Savolainen, S. Schlömer, C. von Stechow, T. Zwickel and J.C. Minx (eds.)]. Cambridge University Press, Cambridge, United Kingdom and New York, NY, USA.

Ivanov, D., Sokolov, B., and Dolgui, A. 2014. "The Ripple effect in supply chains: trade-off 'efficiency-flexibility-resilience' in disruption management." International Journal of Production Research 52 (7): 2154-2172.

Kache, F., Seuring, S. 2014. "Linking collaboration and integration to risk and performance in supply chains via a review of literature reviews. Supply Chain Management: An International Journal, 19 (5/6), $664-682$.

Keleş, B., Gómez-Acevedo, P., and Shaikh, N.I. 2018. "The impact of systematic changes in weather on the supply and demand of beverages." International Journal of Production Economics 195: 186-197.

Kreie, A. 2013. The Adaptation of Supply Chains to Climate Change. PhD Thesis, HeriotWatt University, UK.

Li, L., Cao, R., Wei, K., Wang, W., Chen, L. 2019. "Adapting climate change challenge: A new vulnerability assessment framework from the global perspective." Journal of Cleaner Production 217: 216-224.

Lim-Camacho, L., Plagányi, É.E., Crimp, S., Hodgkinson, J.H., Hobday, A.J., Howden, S.M., Loechel, B. 2017. "Complex resource supply chains display higher resilience to simulated climate shocks." Global Environmental Change 46: 126-138.

McKinnon, A., Browne, M., Whiteing, A., Piecyk, M. -Eds.- 2015. Green Logistics: Improving the Environmental Sustainability of Logistics. London: Kogan Page Publishers. 
Er-Kara, M., Ghadge, A. \& Bititci, US, (2020), "Modelling the impact of climate change risk on supply chain performance", International journal of Production Research, Accepted.

Mehrjoo, M., and Pasek, Z.J. 2016. "Risk assessment for the supply chain of fast fashion apparel industry: a system dynamics framework." International Journal of Production Research 54 (1): 28-48.

Melkonyan, A., Krumme, K., Gruchmann, T., De La Torre, G. 2017. "Sustainability assessment and climate change resilience in food production and supply." Energy Procedia 123: 131-138.

Mital, M., Giudice, M.D., and Papa, A. 2018. "Comparing supply chain risks for multiple product categories with cognitive mapping and Analytic Hierarchy Process." Technological Forecasting and Social Change 131: 159-170.

Neely, A., Gregory, M., and Platts, K. 1995. "Performance measurement system design: A literature review and research agenda." International Journal of Operations \& Production Management 15 (4): 80-116.

OECD 2015. The Economic Consequences of Climate Change. OECD Publishing, Paris. doi:10.1787/9789264235410-en

Ojha, R., Ghadge, A., Tiwari, M. K. and Bititci, U. S. 2018. Bayesian network modelling for supply chain risk propagation. International Journal of Production Research, 56(17): 5795-5819. doi: 10.1080/00207543.2018.1467059.

Olivares-Aguila, J. and ElMaraghy, W. 2020. "System dynamics modelling for supply chain disruptions." International Journal of Production Research. doi:10.1080/00207543.2020.1725171

Özesmi, U., and Özesmi, S.L. 2004. "Ecological models based on people's knowledge: a multi-step fuzzy cognitive mapping approach." Ecological Modelling 176, 43-64.

Quang, H.T., and Hara, Y. 2018. "Risks and performance in supply chain: the push effect." International Journal of Production Research 56 (4): 1369-1388.

Rand, W., and Rust, R.T. 2011. "Agent-based modeling in marketing: Guidelines for rigor." International Journal of Research in Marketing 28 (3): 181-193.

Rathore, R., Thakkar, J.J., and Jha, J.K. 2020. "Impact of risks in foodgrains transportation system: a system dynamics approach.” International Journal of Production Research. doi:10.1080/00207543.2020.1725683

SCC. 2012. Supply Chain Operations Reference Model. Revision 11.0, Supply Chain Council.

Sellitto, M.A., Pereira, G.M., Borchardt, M., da Silva, R.I., Viegas, C.V. 2015. "A SCORbased model for supply chain performance measurement: application in the footwear industry." International Journal of Production Research 53 (16): 4917-4926.

Sousa Jabbour, A.B.L., Jabbour, C.J.C., Sarkis, J., Gunasekaran, A., Alves, M.W.F.M., Ribeiro, D.A. 2018. "Decarbonisation of operations management - looking back, moving forward: a review and implications for the production research community." International Journal of Production Research. doi:10.1080/00207543.2017.1421790

Sterman, J.D. 2000. Business Dynamics: Systems Thinking and Modeling for a Complex World. McGraw-Hill Europe.

Sussman, F.G., and Freed, J.R. 2008. Adapting to Climate Change: A Business Approach. Pew Center on Global Climate Change, Arlington.

Thorpe, J., and Fennell, S. 2012. Climate Change Risks and Supply Chain Responsibility: How should companies respond when extreme weather affects small-scale producers in their supply chain? Oxfam Discussion Papers. Accessed 15 July 2020. https://d1tn3vj7xz9fdh.cloudfront.net/s3fs-public/file_attachments/dp-climate-changerisks-supply-chain-responsibility-27062012-en_5.pdf.

Turken, N., Cannataro, V., Geda, A., Dixit, A. 2020. "Nature inspired supply chain solutions: definitions, analogies, and future research directions." International Journal of Production Research. doi:10.1080/00207543.2020.1778206. 
Er-Kara, M., Ghadge, A. \& Bititci, US, (2020), "Modelling the impact of climate change risk on supply chain performance", International journal of Production Research, Accepted.

\section{Appendix A.}

Table A.1. Some of the input variables for model and associated mathematical equations

\begin{tabular}{|c|c|}
\hline Variable & Equation \\
\hline $\begin{array}{l}\text { Additional inventory } \\
\text { holding cost }\end{array}$ & Blockage length*0.5 \\
\hline $\begin{array}{l}\text { Additional transportation } \\
\text { cost }\end{array}$ & Weather related delay*1 \\
\hline $\begin{array}{l}\text { Availability of raw } \\
\text { materials }\end{array}$ & $(1500 * \operatorname{EXP}(-$ Combined climate effect*Time $))$ \\
\hline Bad weather level & $\begin{array}{l}0.32+\operatorname{STEP}(0.5,12 * 3)+\operatorname{STEP}(0.5,12 * 6)+\operatorname{STEP}(0.5,12 * 9)+\operatorname{STEP} \\
(0.5,12 * 12)+\operatorname{STEP}(0.5,12 * 15)+\operatorname{STEP}(0.5,12 * 18)+\operatorname{STEP}(0.5,12 \\
* 21)+\operatorname{STEP}(0.5,12 * 24)+\operatorname{STEP}(0.5,12 * 27)+\mathrm{STEP}(0.5,12 * 30)+\mathrm{S} \\
\mathrm{TEP}(0.5,12 * 33)+\operatorname{STEP}(0.5,12 * 36)+\operatorname{STEP}(0.5,12 * 39)\end{array}$ \\
\hline Bad weather probability & $\begin{array}{l}((2 / 12)+0.2)+\operatorname{STEP}(0.04,12 * 3)+\operatorname{STEP}(0.04,12 * 6)+\operatorname{STEP}(0.04,1 \\
2 * 9)+\operatorname{STEP}(0.04,12 * 12)+\operatorname{STEP}(0.04,12 * 15)+\operatorname{STEP}(0.04,12 * 18 \\
)+\operatorname{STEP}(0.04,12 * 21)+\operatorname{STEP}(0.04,12 * 24)+\operatorname{STEP}(0.04,12 * 27)+\mathrm{S} \\
\mathrm{TEP}(0.04,12 * 30)+\mathrm{STEP}(0.04,12 * 33)+\mathrm{STEP}(0.04,12 * 36)+\mathrm{STE} \\
\mathrm{P}(0.04,12 * 39)\end{array}$ \\
\hline badweatherRV & RANDOM 01() \\
\hline Blockage length & $\begin{array}{l}\text { IF THEN ELSE (Time=Blockage start, Severity of weather } \\
\text { extreme,0) }\end{array}$ \\
\hline Combined climate effect & $\begin{array}{l}\left(\left(0.5^{*} \text { Temperature increase }+0.3 * \text { Extreme weather }\right.\right. \\
\left.\text { events } 1+0.2 * \text { Decrease in available land }) /\left(2135^{*} 3\right)\right)\end{array}$ \\
\hline Customer Demand & RANDOM NORMAL $(900,1100,1000,20,1)$ \\
\hline Decrease in available land & $5 *$ Climate change \\
\hline $\begin{array}{l}\text { Decrease in delivery } \\
\text { speed }\end{array}$ & $\begin{array}{l}\text { IF THEN ELSE(badweatherRV }<\text { Bad weather } \\
\text { probability, } 1,0) * \text { Extreme weather events } 2\end{array}$ \\
\hline Delays in delivery & $(($ Delivery lead time-7)*100)/7 \\
\hline Delivery lead time & 7+Lead time adjustment \\
\hline Extreme weather events 1 & $6 *$ Climate change \\
\hline Increase in logistics cost & $\begin{array}{l}((\text { Additional transportation cost }+ \text { Additional inventory holding } \\
\left.\text { cost })^{*} 100\right) / 7\end{array}$ \\
\hline Lead time adjustment & MAX(Weather related delay, Blockage length) \\
\hline Manuf Inventory & $\begin{array}{l}\text { INTEGER(Production rate-Product delivery rate) } \\
\text { Initial value: Safety stock }\end{array}$ \\
\hline Manufacturing cost & $10 *$ Production rate \\
\hline $\begin{array}{l}\text { Manufacturing } \\
\text { productivity change }\end{array}$ & $\left((982.1-\text { Production rate })^{*} 100\right) / 982.1$ \\
\hline Mean Blockage Time & $\begin{array}{l}\text { 2.2+STEP }(0.4,12 * 3)+\operatorname{STEP}(0.4,12 * 6)+\operatorname{STEP}(0.4,12 * 9)+\operatorname{STEP}( \\
0.4,12 * 12)+\operatorname{STEP}(0.4,12 * 15)+\operatorname{STEP}(0.4,12 * 18)+\mathrm{STEP}(0.4,12 * \\
21)+\operatorname{STEP}(0.4,12 * 24)+\operatorname{STEP}(0.4,12 * 27)+\operatorname{STEP}(0.4,12 * 30)+\mathrm{ST} \\
\operatorname{EP}(0.4,12 * 33)+\operatorname{STEP}(0.4,12 * 36)+\operatorname{STEP}(0.4,12 * 39)\end{array}$ \\
\hline Overall SC performance & (SC efficiency+SC Effectiveness)/2 \\
\hline Overhead absorbtion rate & Manufacturing cost/Production rate \\
\hline Raw material price & $10+(10 *(1200-$ Availability of raw materials $) / 1200)$ \\
\hline Safety stock & 1200 \\
\hline SC Effectiveness & $\begin{array}{l}100-((0.4 *((100 * \text { Stockout amount }) / 1000)+0.2 *((\text { Deviation in } \\
\text { lead time } * 100) / 7)+0.4 * \text { Delays in delivery }) / 10)\end{array}$ \\
\hline
\end{tabular}


Er-Kara, M., Ghadge, A. \& Bititci, US, (2020), "Modelling the impact of climate change risk on supply chain performance", International journal of Production Research, Accepted.

\begin{tabular}{|l|l|}
\hline SC efficiency & $\begin{array}{l}100-(0.4 *(((\text { Unit cost change-14.5)*100)/14.5)+0.4*(((982.1- } \\
\text { Manufacturing productivity change)*100)/982.1)+0.2*Delays in } \\
\text { delivery }) / 50)\end{array}$ \\
\hline SD of Blockage Time & 2 \\
\hline SD of severity & 0.6 \\
\hline $\begin{array}{l}\text { Severity of weather } \\
\text { extreme }\end{array}$ & $\begin{array}{l}\text { RANDOM NORMAL }(1,9, \text { Mean Blockage Time, SD of } \\
\text { Blockage Time }, 1) * \text { Extreme weather events2 }\end{array}$ \\
\hline Stockout amount & $\begin{array}{l}\text { INTEGER(IF THEN ELSE(Manuf Inventory }>=\text { Customer } \\
\text { Demand,0,Customer Demand-Manuf Inventory) })\end{array}$ \\
\hline Supplier shipment rate & MIN(Supplier's Inventory,Desired production rate) \\
\hline Supply rate & MIN(Supplier shipment rate, Availability of raw materials) \\
\hline Temperature increase & $8 *$ Climate change \\
\hline TIME STEP & 1 \\
\hline Transportation blockage & $\begin{array}{l}\text { INTEGER(RANDOM NORMAL(0, 3, 1, 2,Time) }) * \text { Extreme } \\
\text { weather events2 }\end{array}$ \\
\hline Unit cost change & $\begin{array}{l}(((\text { Raw material price-7.5)*100)/7.5)+Overhead absorbtion } \\
\text { rate+Increase in logistics cost }\end{array}$ \\
\hline Weather related delay & $\begin{array}{l}\text { IF THEN ELSE(Decrease in delivery speed=1,RANDOM } \\
\text { NORMAL(0, 7, Bad weather level, SD of severity, 1),0) }\end{array}$ \\
\hline
\end{tabular}

\section{Appendix B.}

Table B.2. General simulation parameters (Common parameters for all scenarios)

\begin{tabular}{|l|c|}
\hline \multicolumn{1}{|c|}{ Parameter } & Value \\
\hline Initial available raw material & 1500 units \\
\hline Weight of temperature increase & 0.5 \\
\hline Weight of extreme weather events1 & 0.3 \\
\hline Weight of decrease in available land & 0.2 \\
\hline Level of temperature increase & 8 \\
\hline Level of extreme weather events1 & 6 \\
\hline Level of decrease in available land & 5 \\
\hline Supplier's initial inventory level & 1200 units \\
\hline Raw material price at time 0 & 7.5 \$ unit \\
\hline Manufacturing cost & 10 /unit \\
\hline Safety stock & 1200 units \\
\hline Standard delivery lead time & 7 days \\
\hline Additional inventory holding cost during route blockage & $0.5 \$$ unit/day \\
\hline Additional transportation cost due to delays & 1 \$/unit/day \\
\hline
\end{tabular}


Er-Kara, M., Ghadge, A. \& Bititci, US, (2020), "Modelling the impact of climate change risk on supply chain performance", International journal of Production Research, Accepted.

Table B.2. Scenario parameters

\begin{tabular}{|c|c|c|c|c|c|c|c|c|c|}
\hline \multicolumn{10}{|c|}{ Impact of weather events on delivery } \\
\hline \multicolumn{10}{|c|}{ Scenarios } \\
\hline Parameters & S1L1 & S1L2 & $S 1 L 3$ & $S 2 L 1$ & $S 2 L 2$ & $S 2 L 3$ & $S 3 L 1$ & $S 3 L 2$ & $S 3 L 3$ \\
\hline $\begin{array}{r}\text { Mean } \\
\text { blockage time }\end{array}$ & $\begin{array}{c}2 \\
(+0.3 \text { each } 3 \\
\text { years })\end{array}$ & $\begin{array}{c}2.5 \\
(+0.4 \text { each } 3 \\
\text { years })\end{array}$ & $\begin{array}{c}3 \\
(+0.5 \text { each } 3 \\
\text { years })\end{array}$ & $\begin{array}{c}2 \\
(+0.3 \text { each } 3 \\
\text { years })\end{array}$ & $\begin{array}{c}2.5 \\
(+0.4 \text { each } 3 \\
\text { years })\end{array}$ & $\begin{array}{c}3 \\
(+0.5 \text { each } 3 \\
\text { years })\end{array}$ & $\begin{array}{c}2 \\
(+0.3 \text { each } 3 \\
\text { years })\end{array}$ & $\begin{array}{c}2.5 \\
(+0.4 \text { each } 3 \\
\text { years })\end{array}$ & $\begin{array}{c}3 \\
(+0.5 \text { each } 3 \\
\text { years })\end{array}$ \\
\hline $\begin{array}{r}\text { SD of } \\
\text { blockage time }\end{array}$ & 2 & 2.5 & 3 & 2 & 2.5 & 3 & 2 & 2.5 & 3 \\
\hline $\begin{array}{r}\text { Min blockage } \\
\text { length }\end{array}$ & 1 & 1 & 1 & 1 & 1 & 1 & 1 & 1 & 1 \\
\hline $\begin{array}{r}\text { Max blockage } \\
\text { length }\end{array}$ & 9 & 11 & 13 & 9 & 11 & 13 & 9 & 11 & 13 \\
\hline $\begin{array}{r}\text { Bad weather } \\
\text { probability }\end{array}$ & $\begin{array}{c}0.3 \\
(+0.03 \text { each } 3 \\
\text { years })\end{array}$ & $\begin{array}{c}0.4 \\
(+0.04 \text { each } 3 \\
\text { years })\end{array}$ & $\begin{array}{c}0.5 \\
(+0.05 \text { each } 3 \\
\text { years })\end{array}$ & $\begin{array}{c}0.3 \\
(+0.03 \text { each } 3 \\
\text { years })\end{array}$ & $\begin{array}{c}0.4 \\
(+0.04 \text { each } 3 \\
\text { years })\end{array}$ & $\begin{array}{c}0.5 \\
(+0.05 \text { each } 3 \\
\text { years })\end{array}$ & $\begin{array}{c}0.3 \\
(+0.03 \text { each } 3 \\
\text { years })\end{array}$ & $\begin{array}{c}0.4 \\
(+0.04 \text { each } 3 \\
\text { years })\end{array}$ & $\begin{array}{c}0.5 \\
(+0.05 \text { each } 3 \\
\text { years })\end{array}$ \\
\hline $\begin{array}{c}\text { Mean bad } \\
\text { weather level }\end{array}$ & $\begin{array}{c}0.3 \\
(+0.3 \text { each } 3 \\
\text { years })\end{array}$ & $\begin{array}{c}0.4 \\
(+0.4 \text { each } 3 \\
\text { years })\end{array}$ & $\begin{array}{c}0.5 \\
(+0.5 \text { each } 3 \\
\text { years })\end{array}$ & $\begin{array}{c}0.3 \\
(+0.3 \text { each } 3 \\
\text { years })\end{array}$ & $\begin{array}{c}0.4 \\
(+0.4 \text { each } 3 \\
\text { years })\end{array}$ & $\begin{array}{c}0.5 \\
(+0.5 \text { each } 3 \\
\text { years })\end{array}$ & $\begin{array}{c}0.3 \\
(+0.3 \text { each } 3 \\
\text { years })\end{array}$ & $\begin{array}{c}0.4 \\
(+0.4 \text { each } 3 \\
\text { years })\end{array}$ & $\begin{array}{c}0.5 \\
(+0.5 \text { each } 3 \\
\text { years })\end{array}$ \\
\hline SD of severity & 0.6 & 0.7 & 0.8 & 0.6 & 0.7 & 0.8 & 0.6 & 0.7 & 0.8 \\
\hline $\begin{array}{l}\text { Min weather } \\
\text { related delay }\end{array}$ & 0 & 0 & 0 & 0 & 0 & 0 & 0 & 0 & 0 \\
\hline $\begin{array}{l}\text { Max weather } \\
\text { related delay }\end{array}$ & 7 & 9 & 11 & 7 & 9 & 11 & 7 & 9 & 11 \\
\hline
\end{tabular}

